\title{
Peptide-cleavable self-immolative maytansinoid antibody drug conjugates designed to provide improved bystander killing
}

Supporting Information

\section{Contents}

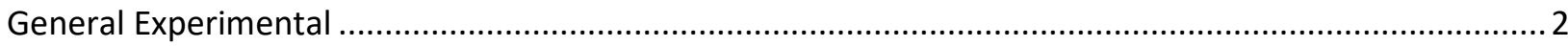

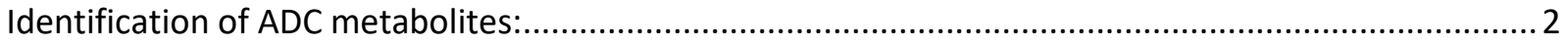

Reason for using COLO-205 cells vs other cell types: ................................................................. 3

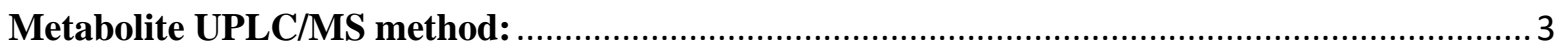

Preparation of immolative ADC payloads ......................................................................................... 4

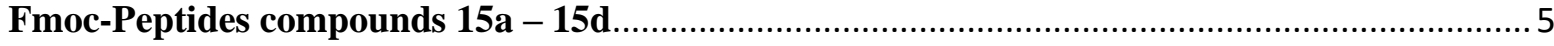

Synthesis of Fmoc-Peptide-OAc compounds 16a - 16d ............................................................ 5

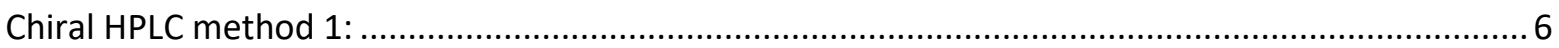

Synthesis of Fmoc-peptide-COOH compounds 17a - 17e .................................................... 6

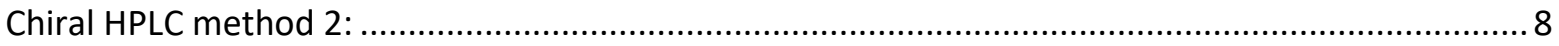

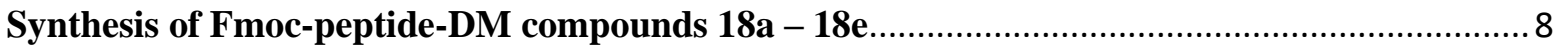

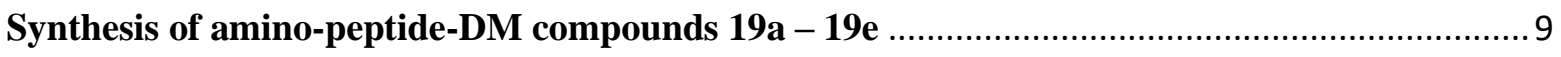

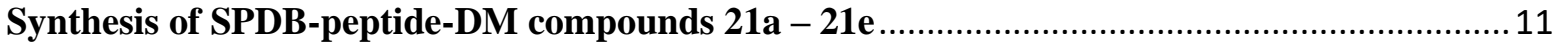

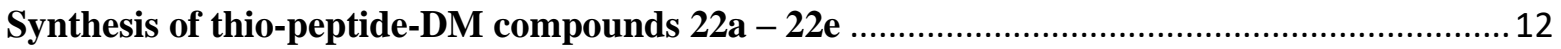

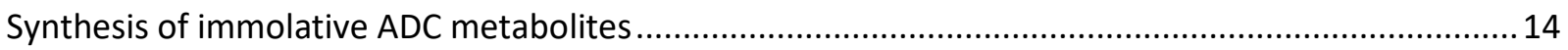

General procedure for the preparation of immolative ADCs. .........................................................17

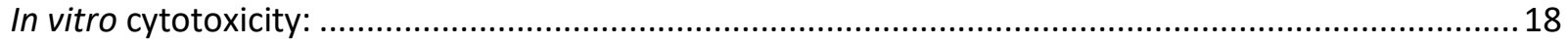

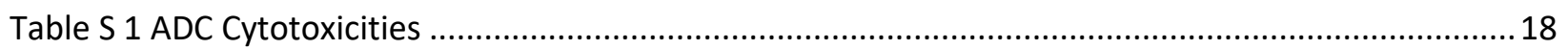

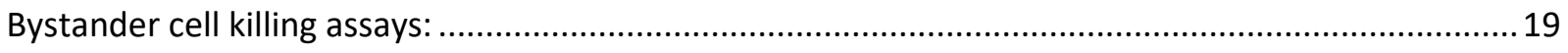

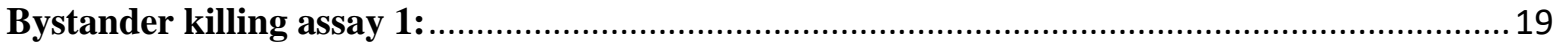

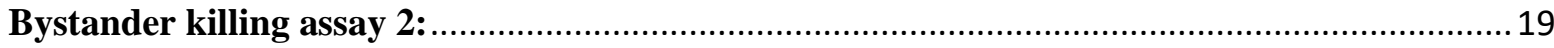

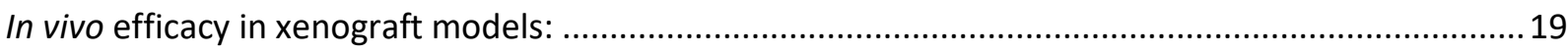

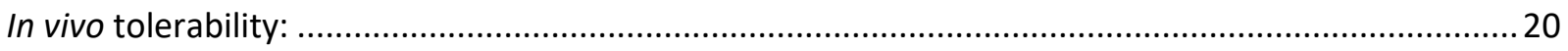

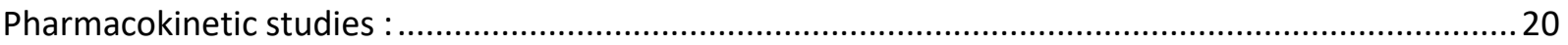

Full list of immolative ADC 7c Pharmaco Kinetic results: ......................................................20 


\section{Figures}

Figure S 1 UPLC $252 \mathrm{~nm}$ absorbance traces of cell lysate from COLO205 cells not treated (Top) or treated with 7c (Bottom). The 12.73 min peak was identified as 12a and the 7.72 min peak was identified as

$12 a^{\prime}$.

Figure $\mathbf{S} 2$ Preparation of immolative ADC Payloads

Figure $S 3$ Preparation of the immolative ADC metabolites 12a, 12b, 12c, 12a' and 12a".....

Figure S 4 Preparation of immolative ADC: The right most amino acid of the linker is attached to the immolative nitrogen example: $(L, L, D)$ indicates a D-Alanyl residue is attached to the immolative nitrogen)

Figure S 5 Binding affinity of representative ADCs to target antigen on T47D cells

\section{General Experimental}

All reagents were obtained from Chem Impex, Bachem, or Sigma-Aldrich unless otherwise stated. All synthetic reactions were conducted under an argon atmosphere with magnetic stirring unless otherwise stated. Proton magnetic resonance $\left({ }^{1} \mathrm{H}\right.$ NMR) and carbon magnetic resonance spectra $\left({ }^{13} \mathrm{C}\right.$ NMR) were obtained on a Bruker Avance 400 spectrometer operating at 400 and $100 \mathrm{MHz}$, respectively. The NMR chemical shifts are reported in $\delta$ values relative to the NMR solvent. Lyophilizations were performed using a VerTis Benchtop K. Flash chromatography was performed on an Agilent Intelliflash system. HPLC purifications were performed using Gilson 334 pumps in series with a Gilson UV/vis-156 dual wavelength detector and a Gilson FC204 fraction collector. High resolution mass spectra were obtained on a Thermo Fisher Q-Exactive instrument. HPLC/LRMS analyses were conducted using an Agilent 1260 HPLC in tandem with an Agilent 6120 single quadrupole mass spectrometer.

\section{Identification of ADC metabolites:}

COLO-205 cells $\left(6 \times 10^{6}\right)$ suspended in $3 \mathrm{~mL}$ culture medium containing the immolative ADC of interest at a concentration of $1 \times 10^{-7} \mathrm{M}$ of conjugated antibody was incubated at $37^{\circ} \mathrm{C}$ for $24 \mathrm{~h}$. The cells and medium were then mixed with ice-cold acetone $(4 \mathrm{~mL})$, and kept at $-20^{\circ} \mathrm{C}$ for at least I hour or until further processing. The sample was allowed to warm to room temperature then $\mathrm{N}$-ethylmaleimide was added to $7.5 \mathrm{mmol} / \mathrm{L}$, vortexed for $2 \mathrm{~min}$ then kept at room temperature for $30 \mathrm{~min}$. The sample was centrifuged at 2,500 $\mathrm{xg}$. The supernatant was transferred to a separate conical vial and solvent was evaporated to dryness by centrifugation under vacuum. The sample was dissolved in $30 \%$ aqueous acetonitrile $(0.12 \mathrm{~mL})$ and analyzed using the Metabolite UPLC/MS method.

Separate samples of $12 \mathrm{a}$ and $\mathbf{1 2} \mathrm{a}^{\prime}$ both in $30 \%$ aqueous acetonitrile $\left(\sim 3 \times 10^{-5} \mathrm{M}\right)$ were prepared and analyzed by the Metabolite UPLC/MS method. The $12 \mathrm{a}$ sample was also reanalyzed after $5 \mathrm{~h}$ at room temperature. 
Reason for using COLO-205 cells vs other cell types: COLO-205 cells can bind millions of antiCanAg bearing ADCs, while most cell lines can only bind a few hundred thousand or less of a targeted conjugate. This allows COLO-205 cells to produce far more ADC metabolite than most other cell lines. Other cell lines could potentially be used however orders of magnitude more of them would be needed to produce the same amount of metabolite, which would produce orders of magnitude more cell debris in HPLC assays.

\section{Metabolite UPLC/MS method:}

A Dionex UltiMate 3000 UPLC was equipped with a Waters UPLC BEH C8, $1.8 \mu \mathrm{m}, 100 \times 2.1 \mathrm{~mm}$ column maintained at $30^{\circ} \mathrm{C}$, outflow following UV detection ( $252 \mathrm{~nm}$ ) went to a Thermo Q-Exactive mass spectrometer. The column was eluted with solvent $A$ (deionized water containing $0.1 \%$ formic acid) and linear gradient of $20-100 \%$ from time $0-20$ min with solvent $B$ (acetonitrile containing $0.1 \%$ formic acid), flow rate $0.35 \mathrm{~mL} / \mathrm{min}$, UV detection $252 \mathrm{~nm}$. Sample injection volume $40 \mu \mathrm{L}$.

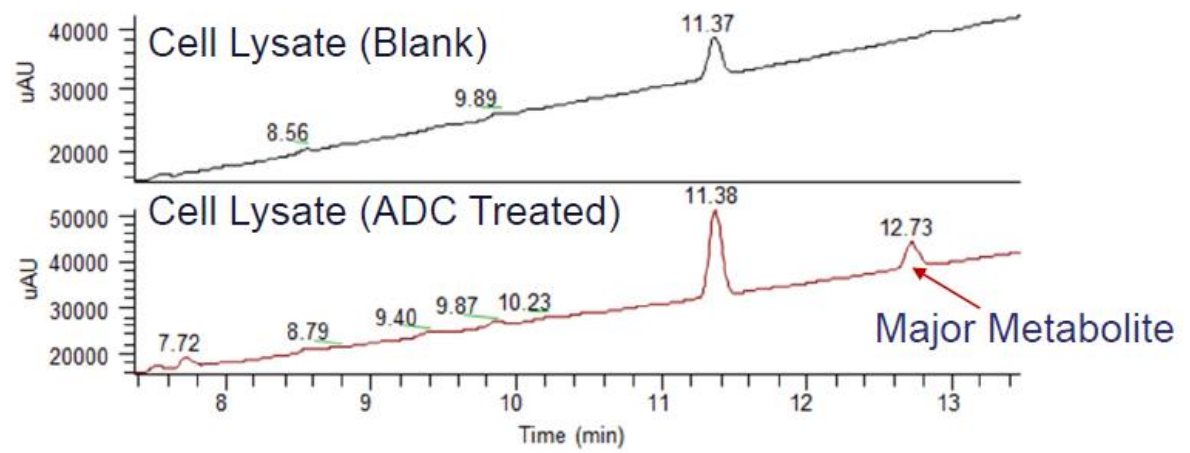

Figure S 1 UPLC $252 \mathrm{~nm}$ absorbance traces of cell lysate from COLO205 cells not treated (Top) or treated with 7c (Bottom). The 12.73 min peak was identified as 12a and the 7.72 min peak was identified as 12a'. 


\section{Preparation of immolative ADC payloads}
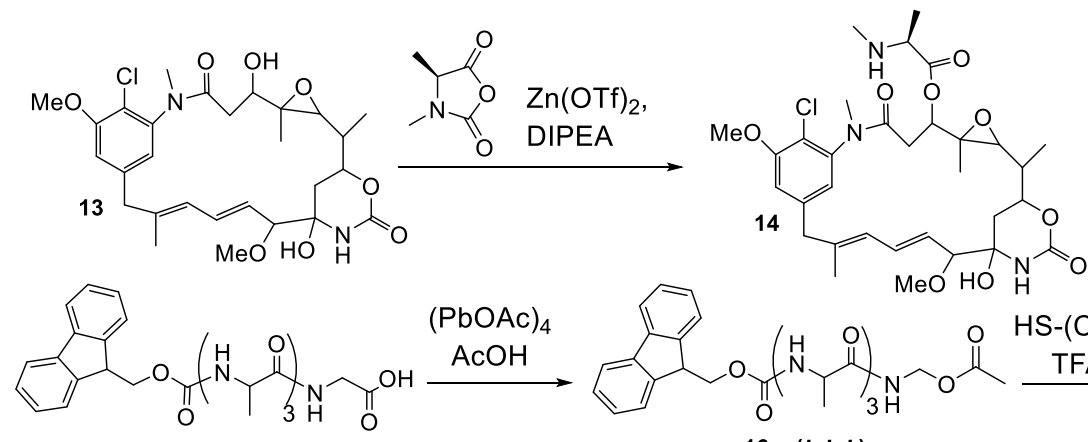

15a $(L, L, L)$
$15 \mathrm{~b}(D, L, L)$
$15 \mathrm{c}(L, D, L)$
$15 \mathrm{~d}(L, L, D)$

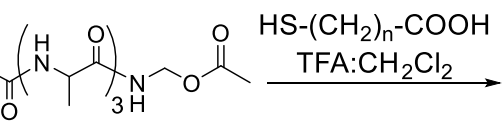

$16 \mathrm{a}(L, L, L)$

$16 \mathrm{~b}(D, L, L)$

$16 \mathrm{c}(L, D, L)$

$16 \mathrm{~d}(L, L, D)$
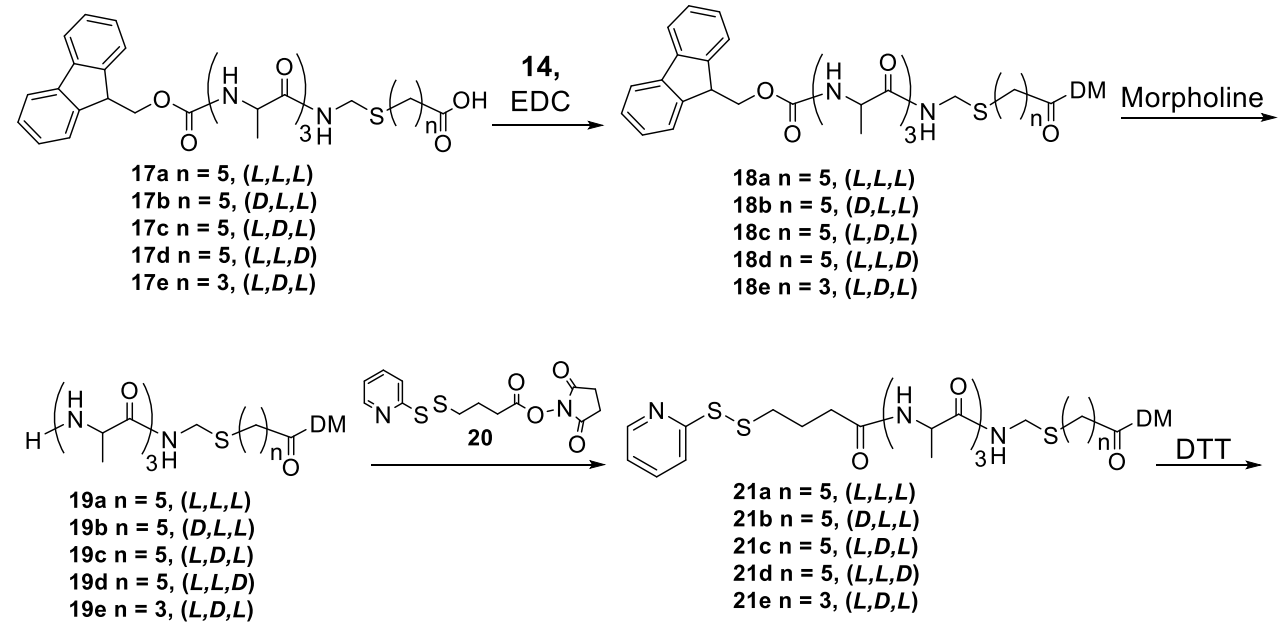

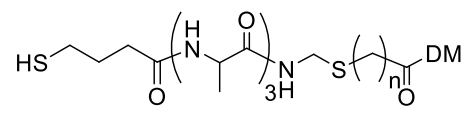

22a $\mathrm{n}=5,(L, L, L)$

22b $\mathrm{n}=5,(D, L, L)$

22c $\mathrm{n}=5,(L, D, L)$

22d $\mathrm{n}=5,(L, L, D)$

22e $\mathrm{n}=3,(L, D, L)$

Figure S 2 Preparation of immolative ADC Payloads

Immolative ADC payloads were prepared as depicted in Figure S 2, Maytansinol (13) was reacted with the $N$-carboxyanhydride of $L-N$-methyl alanine followed by an aqueous quench to give the $N$-methyl alanine ester of maytansinol (14, DM-H). Fmoc protected peptides $(\mathbf{1 5 a}-\mathbf{1 5 d})$ were prepared by solid phase synthesis using standard procedures. The protected peptides were then oxidatively decarboxylated with lead tetraacetate to give the acetates $(\mathbf{1 6 a}-\mathbf{1 6 d})$. These compounds were then reacted with mercapto-acids of various lengths in the presence of trifluoroacetic acid to give compounds $(\mathbf{1 7 a}-\mathbf{1 7 e})$. Further reaction with DM-H (14) and 1Ethyl-3-(3-dimethylaminopropyl) carbodiimide (EDC) coupling agent gave compounds (18a- 
18e) which were then deprotected using morpholine as base. The resulting compounds (19a19e) were reacted with the cross linker SPDB $(20)$ to give $(21 \mathbf{a}-\mathbf{2 1 e})$ which were reacted with 1, 4-Dithio-DL-threitol (DTT) to give (22a - 22e). The immolative ADCs (6a-6d) (7c, 7e), $(\mathbf{8 a}, \mathbf{8 c})$ and $9 \mathbf{c}$ were then prepared by reacting sulfo-GMBS (23) with one of the humanized antibodies anti-EGFR (anti-huEGFR), anti-folate receptor (anti-huFR $\alpha$ ), anti-CanAg (antihuCanAg) or anti-hucMet (anti-hucMet) and the corresponding compound (22a-22e).

DM-H (14) stock solution: Maytansinol (13, $5.0 \mathrm{~g}, 8.85 \mathrm{mmol})$ was dissolved in anhydrous DMF (125 mL) then cooled in an ice bath. The $N$-carboxyanhydride of $N$-methyl alanine $(5.7 \mathrm{~g}$, $44.25 \mathrm{mmol})$, anhydrous DIPEA $(7.70 \mathrm{~mL}, 44.25 \mathrm{mmol})$ and zinc trifluoromethane sulfonate $(22.5 \mathrm{~g}, 62 \mathrm{mmol})$ were then added and magnetic stirred under an argon atmosphere. The ice bath was removed and the reaction was allowed to warm to room temperature with stirring. After $16 \mathrm{~h}$, deionized water $(10 \mathrm{~mL})$ was added. After $30 \mathrm{~min}$ a 1:1 solution of saturated aqueous sodium bicarbonate: saturated aqueous sodium chloride $(190 \mathrm{~mL})$ and ethyl acetate $(250$ $\mathrm{mL}$ ) were added with vigorous stirring. The mixture was transferred to a separatory funnel and the organic layer was retained. The aqueous layer was extracted with ethyl acetate $(100 \mathrm{~mL})$ then the organic layers were combined and washed with saturated aqueous sodium chloride (50 $\mathrm{mL}$ ). The organic layer was concentrated to approximately $1 / 4$ th its volume by rotary evaporation under vacuum without heating, no purification was conducted. The concentration of the solution was estimated by dividing the mmoles of maytansinol used in the reaction (1.77 $\mathrm{mmol})$ by the volume $(150 \mathrm{~mL})$ giving DM-H stock solution $(0.06 \mathrm{mmol} / \mathrm{mL})$. Aliqouts of the stock solution were immediately dispensed then used in reactions or stored in a $-80 \mathrm{C}$ freezer then thawed when needed. HPLC/LRMS $(\mathrm{M}+\mathrm{H})+$ calcd. 650.3 Found 650.5.

\section{Fmoc-Peptides compounds 15a - 15d}

Prepared by solid phase synthesis at Pharmaron Inc.

15a LRMS (M + Na)+ calcd. 533.2 Found 533.4

15b LRMS (M + Na)+ calcd. 533.2 Found 533.3

15c LRMS $(\mathrm{M}+\mathrm{Na})+$ calcd. 533.2 Found 533.3

15d LRMS $(\mathrm{M}+\mathrm{Na})+$ calcd. 533.2 Found 533.5

\section{Synthesis of Fmoc-Peptide-OAc compounds 16a - 16d}

Compounds of the type Fmoc-Peptide-NH- $\mathrm{CH}_{2}-\mathrm{OAc}$ were prepared as shown for Fmoc-L-AlaL-Ala-L-Ala-NH-CH -OAc.

Fmoc- $L$-Ala- $L$-Ala- $L$-Ala-NH-CH2-OAc (16a): Fmoc- $L$-Ala- $L$-Ala- $L$-Ala-Gly-OH (500 mg, $0.979 \mathrm{mmol}$ ) was dissolved in DMF ( $2 \mathrm{~mL}$ ), to which was added copper (II) acetate (17.8 $\mathrm{mg}$, $0.098 \mathrm{mmol})$ and acetic acid ( $84 \mu \mathrm{L}, 1.47 \mathrm{mmol})$ with magnetic stirring under argon. Once solids were dissolved, lead tetraacetate $(434 \mathrm{mg}, 0.979 \mathrm{mmol})$ was added, The reaction was allowed to proceed at $60^{\circ} \mathrm{C}$ for 20 min then purified on a C18, 30 micron $450 \mathrm{~g}$ column cartridge, eluting with deionized water containing $0.1 \%$ formic acid and an linear acetonitrile 
gradient of 5\% to $55 \%$ over $26 \mathrm{~min}$ at a flow rate of $125 \mathrm{~mL} / \mathrm{min}$. Fractions containing pure desired product were frozen and lyopholized to give $178 \mathrm{mg}$ (34\% yield) of a white solid. HRMS $(\mathrm{M}+\mathrm{Na})^{+}$calcd. 547.2163; found 547.2160. ${ }^{1} \mathrm{H}$ NMR (400 MHz, DMSO- $\left.d 6\right) \delta 1.20$ (qd, $J=7.5,6.9,4.2 \mathrm{~Hz}, 9 \mathrm{H}), 1.91-2.05(\mathrm{~m}, 3 \mathrm{H}), 3.26-3.38(\mathrm{~m}, 1 \mathrm{H}), 4.05(\mathrm{q}, J=7.3 \mathrm{~Hz}, 1 \mathrm{H})$, $4.23(\mathrm{td}, J=11.9,10.7,6.4 \mathrm{~Hz}, 5 \mathrm{H}), 5.07(\mathrm{ddd}, J=11.2,6.9,4.3 \mathrm{~Hz}, 2 \mathrm{H}), 7.32(\mathrm{q}, J=7.5 \mathrm{~Hz}$, $2 \mathrm{H}), 7.41(\mathrm{q}, J=7.4 \mathrm{~Hz}, 2 \mathrm{H}), 7.52(\mathrm{t}, J=6.8 \mathrm{~Hz}, 1 \mathrm{H}), 7.71(\mathrm{q}, J=7.5,7.0 \mathrm{~Hz}, 2 \mathrm{H}), 7.82-8.08$ $(\mathrm{m}, 4 \mathrm{H}), 8.84(\mathrm{q}, J=7.1 \mathrm{~Hz}, 1 \mathrm{H})$.

Fmoc-D-Ala- $\boldsymbol{L}$-Ala- $\boldsymbol{L}$-Ala-NH-CH $\mathbf{2}-\mathrm{OAc}$ (16b): HRMS $(\mathrm{M}+\mathrm{Na})^{+}$calcd. 547.2163, found 547.2167. ${ }^{1} \mathrm{H}$ NMR (400 MHz, DMSO-d6) $\delta 1.23$ (dd, $\left.J=12.5,7.4 \mathrm{~Hz}, 9 \mathrm{H}\right), 1.95$ (s, 2H), $4.00-$ $4.13(\mathrm{~m}, 1 \mathrm{H}), 4.17-4.38(\mathrm{~m}, 6 \mathrm{H}), 5.06(\mathrm{q}, J=8.8 \mathrm{~Hz}, 2 \mathrm{H}), 7.33(\mathrm{t}, J=7.3 \mathrm{~Hz}, 2 \mathrm{H}), 7.42(\mathrm{t}, J=$ $7.4 \mathrm{~Hz}, 2 \mathrm{H}), 7.62(\mathrm{~d}, J=6.8 \mathrm{~Hz}, 1 \mathrm{H}), 7.71(\mathrm{t}, J=8.6 \mathrm{~Hz}, 2 \mathrm{H}), 7.85-8.01(\mathrm{~m}, 3 \mathrm{H}), 8.21(\mathrm{~d}, J=$ $7.0 \mathrm{~Hz}, 1 \mathrm{H}), 8.69(\mathrm{~d}, J=6.9 \mathrm{~Hz}, 1 \mathrm{H})$.

Fmoc- $L$-Ala- $D$-Ala- $L$-Ala-NH-CH $\mathbf{C H}_{2}-\mathrm{OAc}(\mathbf{1 6 c})$ : HRMS $(\mathrm{M}+\mathrm{Na})^{+}$calcd. 547.2163, found 547.2168. ${ }^{1} \mathrm{H}$ NMR (400 MHz, DMSO-d6) $\delta 1.16-1.24$ (m, 9H), 1.97 (s, 3H), 4.07 (q, $J=7.0$ $\mathrm{Hz}, 1 \mathrm{H}), 4.16-4.34(\mathrm{~m}, 5 \mathrm{H}), 5.00-5.16(\mathrm{~m}, 2 \mathrm{H}), 7.33(\mathrm{td}, J=7.4,1.1 \mathrm{~Hz}, 2 \mathrm{H}), 7.42(\mathrm{t}, J=7.4$ $\mathrm{Hz}, 2 \mathrm{H}), 7.58(\mathrm{~d}, J=7.0 \mathrm{~Hz}, 1 \mathrm{H}), 7.72(\mathrm{t}, J=8.1 \mathrm{~Hz}, 2 \mathrm{H}), 7.90(\mathrm{~d}, J=7.5 \mathrm{~Hz}, 2 \mathrm{H}), 8.03(\mathrm{~d}, J=$ $7.5 \mathrm{~Hz}, 1 \mathrm{H}), 8.14(\mathrm{~d}, J=7.2 \mathrm{~Hz}, 1 \mathrm{H}), 8.85(\mathrm{t}, J=6.9 \mathrm{~Hz}, 1 \mathrm{H})$.

Fmoc- $L$-Ala- $L$-Ala-D-Ala-NH-CH2-OAc (16d): HRMS $(\mathrm{M}+\mathrm{Na})^{+}$calcd. 547.2163 , found 547.2167. ${ }^{1} \mathrm{H}$ NMR (400 MHz, DMSO-d6) $\delta 1.18-1.25$ (m, 9H), 1.97 (s, 3H), $3.96-4.15$ (m, $1 \mathrm{H}), 4.17-4.36(\mathrm{~m}, 5 \mathrm{H}), 5.09(\mathrm{~d}, J=6.9 \mathrm{~Hz}, 2 \mathrm{H}), 7.34(\mathrm{t}, J=7.4 \mathrm{~Hz}, 2 \mathrm{H}), 7.42(\mathrm{t}, J=7.4 \mathrm{~Hz}$, 2H), $7.57(\mathrm{~d}, J=7.2 \mathrm{~Hz}, 1 \mathrm{H}), 7.71(\mathrm{~d}, J=7.3 \mathrm{~Hz}, 2 \mathrm{H}), 7.90(\mathrm{~d}, J=7.5 \mathrm{~Hz}, 2 \mathrm{H}), 8.07$ (s, 2H), $8.86(\mathrm{~s}, 1 \mathrm{H})$.

Fmoc-Ala-Ala-AlaNH-CH $2-\mathrm{OAc}$ compounds $\mathbf{1 6 a}-\mathbf{1 6 d}$ were analyzed using chiral HPLC method 1. A co-injection of the four compounds showed the following retention times 16a (15.5 $\mathrm{min}), \mathbf{1 6 b}(18.1 \mathrm{~min}), \mathbf{1 6 c}(13.6 \mathrm{~min}), \mathbf{1 6 d}(14.4 \mathrm{~min})$. Injection of each compound individually gave a single peak at the compounds corresponding retention time, indicating that the oxidative decarboxylation did not cause racemization of peptide stereochemistry.

Chiral HPLC method 1:

Column: Phenomenex Lux cellulose 1 ( 250 x $4.6 \mathrm{~mm})$

Elution: Isocratic with $92: 8$ hexane:ethanol $0.5 \mathrm{~mL} / \mathrm{min} 40 \mathrm{~min}$

Detection: $250 \mathrm{~nm}$

\section{Synthesis of Fmoc-peptide-COOH compounds 17a - 17e}

Compounds of the type Fmoc-Peptide-NH-CH$-\mathrm{CH}_{2}-\mathrm{S}-\left(\mathrm{CH}_{2}\right)_{\mathrm{n}}-\mathrm{CO}_{2} \mathrm{H}$ were prepared as shown for Fmoc- $L$-Ala- $L$-Ala- $L$-Ala-NH- $\mathrm{CH}_{2}-\mathrm{S}-\left(\mathrm{CH}_{2}\right)_{5}-\mathrm{CO}_{2} \mathrm{H}$. 
Fmoc- $L$-Ala- $L-A l a-L-A l a-N H-C H_{2}-S-\left(\mathrm{CH}_{2}\right)_{5}-\mathbf{C O}_{2} \mathrm{H}$ (17a): 6-mercaptohexanoic acid $(287 \mu \mathrm{L}$, $2.07 \mathrm{mmol})$ was dissolved in a solution of 1:4 TFA: dichloromethane $(5 \mathrm{~mL})$, then added to a vial containing Fmoc- $L$-Ala- $L$-Ala- $L-A l a-N H-C_{2}-\mathrm{OAc}(178 \mathrm{mg}, 0.339 \mathrm{mmol})$. The reaction was allowed to proceed with magnetic stirring under an argon atmosphere at room temperature for $20 \mathrm{~min}$. The crude material was concentrated under vacuum, redissolved in a minimum volume of DMF and purified on a C18 30 micron, 30g cartridge eluting with deionized water containing $0.1 \%$ formic acid with a linear gradient of acetonitrile from $5 \%$ to $95 \%$ over 13 min at $35 \mathrm{~mL} / \mathrm{min}$. Fractions containing pure desired product were frozen and lyophilized to give 200 mg (96\% yield) of a white solid. HRMS $(\mathrm{M}+\mathrm{H})^{+}$calcd. 613.2690; found 613.2686. ${ }^{1} \mathrm{H} \mathrm{NMR}$ (400 MHz, DMSO-d6) $\delta 1.20$ (dt, $J=7.1,4.9 \mathrm{~Hz}, 10 \mathrm{H}), 1.31(\mathrm{tt}, J=10.1,6.0 \mathrm{~Hz}, 2 \mathrm{H}), 1.49$ (dq, $J=12.5,7.4 \mathrm{~Hz}, 4 \mathrm{H}), 2.18(\mathrm{t}, J=7.3 \mathrm{~Hz}, 2 \mathrm{H}), 4.05(\mathrm{t}, J=7.3 \mathrm{~Hz}, 1 \mathrm{H}), 4.16-4.30(\mathrm{~m}, 7 \mathrm{H}), 7.33$ $(\mathrm{td}, J=7.4,1.2 \mathrm{~Hz}, 2 \mathrm{H}), 7.42(\mathrm{td}, J=7.3,1.1 \mathrm{~Hz}, 2 \mathrm{H}), 7.54(\mathrm{~d}, J=7.4 \mathrm{~Hz}, 1 \mathrm{H}), 7.72(\mathrm{t}, J=7.0$ $\mathrm{Hz}, 2 \mathrm{H}), 7.89$ (d, J=7.5 Hz, 2H), $7.94-8.07(\mathrm{~m}, 2 \mathrm{H}), 8.44(\mathrm{t}, J=6.1 \mathrm{~Hz}, 1 \mathrm{H})$.

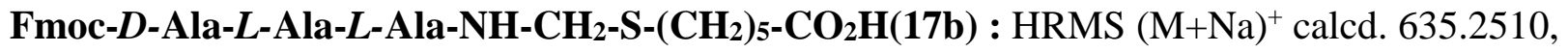
found 635.2515. ${ }^{1} \mathrm{H}$ NMR (400 MHz, DMSO-d6) $\delta 1.15(\mathrm{~d}, J=6.8 \mathrm{~Hz}, 3 \mathrm{H}), 1.18-1.25(\mathrm{~m}$, $10 \mathrm{H}), 2.18(\mathrm{q}, J=7.5 \mathrm{~Hz}, 4 \mathrm{H}), 2.40-2.48(\mathrm{~m}, 1 \mathrm{H}), 2.70(\mathrm{t}, J=7.2 \mathrm{~Hz}, 1 \mathrm{H}), 4.15-4.30(\mathrm{~m}$, $6 \mathrm{H}), 6.29$ (s, 2H), $7.34(\mathrm{q}, J=7.3 \mathrm{~Hz}, 3 \mathrm{H}), 7.42(\mathrm{t}, J=7.4 \mathrm{~Hz}, 3 \mathrm{H}), 7.63-7.78(\mathrm{~m}, 1 \mathrm{H}), 7.85(\mathrm{~d}$, $J=7.3 \mathrm{~Hz}, 2 \mathrm{H}), 7.89(\mathrm{~d}, J=7.5 \mathrm{~Hz}, 3 \mathrm{H}), 8.37-8.46(\mathrm{~m}, 1 \mathrm{H})$.

Fmoc- $L$-Ala-D-Ala- $L-A l a-N H-C H_{2}-S-\left(\mathrm{CH}_{2}\right)_{5}-\mathrm{CO}_{2} \mathrm{H}(\mathbf{1 7 c}): \mathrm{HRMS}(\mathrm{M}+\mathrm{Na})^{+}$calcd. 635.2510 , found 635.2514. ${ }^{1} \mathrm{H}$ NMR (400 MHz, DMSO-d6) $\delta 1.18-1.23(\mathrm{~m}, 10 \mathrm{H}), 1.34$ (q, $J=3.4 \mathrm{~Hz}$, $5 \mathrm{H}), 2.24(\mathrm{~s}, 2 \mathrm{H}), 2.44(\mathrm{~s}, 2 \mathrm{H}), 4.05(\mathrm{t}, J=7.1 \mathrm{~Hz}, 1 \mathrm{H}), 4.16-4.35(\mathrm{~m}, 8 \mathrm{H}), 7.33(\mathrm{t}, J=7.4 \mathrm{~Hz}$, 2H), $7.42(\mathrm{t}, J=7.5 \mathrm{~Hz}, 2 \mathrm{H}), 7.58(\mathrm{~d}, J=7.0 \mathrm{~Hz}, 1 \mathrm{H}), 7.71(\mathrm{t}, J=8.4 \mathrm{~Hz}, 2 \mathrm{H}), 7.90(\mathrm{~s}, 1 \mathrm{H}), 7.98$ $(\mathrm{d}, J=7.5 \mathrm{~Hz}, 1 \mathrm{H}), 8.15(\mathrm{~d}, J=7.3 \mathrm{~Hz}, 1 \mathrm{H}), 8.39(\mathrm{t}, J=6.2 \mathrm{~Hz}, 1 \mathrm{H}), 11.98(\mathrm{~s}, 1 \mathrm{H})$.

Fmoc- $\boldsymbol{L}$-Ala- $\boldsymbol{L}$-Ala- $\boldsymbol{D}$-Ala-NH-CH $2-\mathrm{S}-\left(\mathrm{CH}_{2}\right)_{5}-\mathrm{CO}_{2} \mathrm{H}(\mathbf{1 7 d}): \mathrm{HRMS}(\mathrm{M}+\mathrm{Na})^{+}$calcd. 635.2510 , found 635.2510. ${ }^{1} \mathrm{H}$ NMR (400 MHz, DMSO-d6) $\delta 1.15(\mathrm{~d}, J=6.9 \mathrm{~Hz}, 3 \mathrm{H}), 1.21(\mathrm{~d}, J=7.1 \mathrm{~Hz}$, $9 \mathrm{H}), 1.28-1.38(\mathrm{~m}, 3 \mathrm{H}), 1.44-1.60(\mathrm{~m}, 5 \mathrm{H}), 2.13-2.22(\mathrm{~m}, 3 \mathrm{H}), 3.33(\mathrm{q}, J=6.9 \mathrm{~Hz}, 1 \mathrm{H})$, $4.20(\mathrm{~s}, 2 \mathrm{H}), 6.29(\mathrm{~s}, 2 \mathrm{H}), 7.29-7.40(\mathrm{~m}, 3 \mathrm{H}), 7.38-7.47(\mathrm{~m}, 3 \mathrm{H}), 7.85(\mathrm{~d}, J=7.5 \mathrm{~Hz}, 2 \mathrm{H})$, $7.89(\mathrm{~d}, J=7.5 \mathrm{~Hz}, 2 \mathrm{H}), 8.26(\mathrm{~d}, J=7.6 \mathrm{~Hz}, 1 \mathrm{H}), 8.48(\mathrm{~d}, J=6.2 \mathrm{~Hz}, 1 \mathrm{H})$.

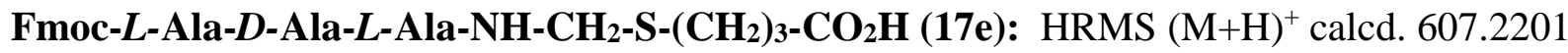
found 607.2204 .

Fmoc-Ala-Ala-AlaNH-CH $2-S$ - compounds $17 \mathbf{a}-\mathbf{1 7 d}$ were analyzed using chiral HPLC method 2. A co-injection of the four compounds showed the following retention times $\mathbf{1 7 a}$ (10.25 $\mathrm{min}$ ), $\mathbf{1 7 b}(12.1 \mathrm{~min}), \mathbf{1 7} \mathbf{c}(7.71 \mathrm{~min}), \mathbf{1 7 d}$ (9.85 $\mathrm{min})$. Injection of each compound individually gave a single peak at its corresponding retention time, indicating that acetate displacement did not cause racemization of peptide stereochemistry. 
Chiral HPLC method 2:

Column: Phenomenex Lux cellulose $1(250$ x $4.6 \mathrm{~mm})$

Elution: Isocratic with $85: 15$ hexane:ethanol, $0.5 \mathrm{~mL} / \mathrm{min}, 24 \mathrm{~min}$

Detection: $250 \mathrm{~nm}$

\section{Synthesis of Fmoc-peptide-DM compounds 18a - 18e}

Compounds of the type Fmoc-Peptide-NH-CH $2-\mathrm{S}-\left(\mathrm{CH}_{2}\right)_{\mathrm{n}}-\mathrm{CO}_{2}-\mathrm{DM}$ were prepared as shown for Fmoc- $L$-Ala- $L$-Ala- $L$-Ala-NH- $\mathrm{CH}_{2}-\mathrm{S}-\left(\mathrm{CH}_{2}\right)_{5}$-CO-DM.

Fmoc- $L$-Ala- $L$-Ala- $L$-Ala-NH-CH -S- $\left(\mathbf{C H}_{2}\right)_{5}$-CO-DM (18a): To DM-H (5) stock solution (8.2 $\mathrm{mL}, 0.49 \mathrm{mmol}$ ) was added Fmoc- $L$-Ala- $L$-Ala- $L$-Ala-NH-CH $2-\mathrm{S}-\left(\mathrm{CH}_{2}\right)_{5}-\mathrm{COOH}(300 \mathrm{mg}, 0.49$ $\mathrm{mmol})$, EDC (94 $\mathrm{mg}, 0.490 \mathrm{mmol})$ and DIPEA $(90 \mu \mathrm{L}, 0.49 \mathrm{mmol})$. The reaction was allowed to proceed with magnetic stirring at room temperature under argon atmosphere for $2 \mathrm{~h}$. The crude material was concentrated by rotary evaporation under vacuum and residue was taken up in a minimum volume of DMF then purified on a $\mathrm{C} 18,30$ micron, $30 \mathrm{~g}$ cartridge eluting with deionized water containing $0.1 \%$ formic acid and a linear gradient of acetonitrile from $5 \%$ to $50 \%$ over $25 \mathrm{~min}$. Fractions containing pure desired product were frozen and lyophilized to yield $151 \mathrm{mg}$, (37.2\% yield) of white solid. HRMS $(\mathrm{M}+\mathrm{Na})^{+}$calcd. 1266.5170; found 1266.5141 . ${ }^{1} \mathrm{H}$ NMR (400 MHz, DMSO- $\left.d 6\right) \delta 0.77(\mathrm{~s}, 3 \mathrm{H}), 1.12(\mathrm{~d}, J=6.4 \mathrm{~Hz}, 3 \mathrm{H}), 1.14-1.22(\mathrm{~m}, 12 \mathrm{H})$, $1.22-1.30(\mathrm{~m}, 3 \mathrm{H}), 1.35-1.49(\mathrm{~m}, 4 \mathrm{H}), 1.50-1.55(\mathrm{~m}, 1 \mathrm{H}), 1.59(\mathrm{~s}, 3 \mathrm{H}), 2.00-2.07(\mathrm{~m}, 1 \mathrm{H})$, 2.14 (ddd, $J=15.6,8.7,5.9 \mathrm{~Hz}, 1 \mathrm{H}$ ), 2.40 (dtd, $J=17.0,7.9,7.0,4.9 \mathrm{~Hz}, 3 \mathrm{H}), 2.69$ (s, 3H), 2.79 (d, $J=9.6 \mathrm{~Hz}, 1 \mathrm{H}), 3.08(\mathrm{~s}, 3 \mathrm{H}), 3.20(\mathrm{~d}, J=12.6 \mathrm{~Hz}, 1 \mathrm{H}), 3.24(\mathrm{~s}, 3 \mathrm{H}), 3.43(\mathrm{~d}, J=12.4 \mathrm{~Hz}$, 2H), $3.48(\mathrm{~d}, J=8.9 \mathrm{~Hz}, 1 \mathrm{H}), 3.92(\mathrm{~s}, 3 \mathrm{H}), 4.08(\mathrm{ddd}, J=20.8,10.8,5.0 \mathrm{~Hz}, 3 \mathrm{H}), 4.14-4.24$ (m, 4H), $4.26(\mathrm{~d}, J=6.0 \mathrm{~Hz}, 3 \mathrm{H}), 4.52(\mathrm{dd}, J=12.0,2.8 \mathrm{~Hz}, 1 \mathrm{H}), 5.34(\mathrm{q}, J=6.7 \mathrm{~Hz}, 1 \mathrm{H}), 5.56$ $(\mathrm{dd}, J=14.7,9.0 \mathrm{~Hz}, 1 \mathrm{H}), 5.91(\mathrm{~s}, 1 \mathrm{H}), 6.50-6.66(\mathrm{~m}, 3 \mathrm{H}), 6.88(\mathrm{~s}, 1 \mathrm{H}), 7.17(\mathrm{~d}, J=1.8 \mathrm{~Hz}$, $1 \mathrm{H}), 7.33(\mathrm{td}, J=7.5,1.2 \mathrm{~Hz}, 2 \mathrm{H}), 7.41(\mathrm{t}, J=7.4 \mathrm{~Hz}, 2 \mathrm{H}), 7.53(\mathrm{~d}, J=7.4 \mathrm{~Hz}, 1 \mathrm{H}), 7.72(\mathrm{t}, J=$ $7.0 \mathrm{~Hz}, 2 \mathrm{H}), 7.89$ (d, $J=7.5 \mathrm{~Hz}, 3 \mathrm{H}), 7.99(\mathrm{~d}, J=7.3 \mathrm{~Hz}, 1 \mathrm{H}), 8.36(\mathrm{t}, J=6.3 \mathrm{~Hz}, 1 \mathrm{H})$.

Fmoc-D-Ala- $L$-Ala- $L$-Ala-NH-CH2-S-(CH2) 5 -CO-DM (18b): HRMS $(\mathrm{M}+\mathrm{Na})^{+}$calcd. 1266.5170, found 1266.5164. ${ }^{1} \mathrm{H}$ NMR (400 MHz, DMSO-d6) $\delta 0.78$ (s, 3H), 1.14 (dd, $J=14.6$, $6.5 \mathrm{~Hz}, 6 \mathrm{H}), 1.22(\mathrm{t}, J=6.8 \mathrm{~Hz}, 10 \mathrm{H}), 1.33-1.57(\mathrm{~m}, 4 \mathrm{H}), 1.59(\mathrm{~s}, 3 \mathrm{H}), 2.04(\mathrm{~d}, J=13.5 \mathrm{~Hz}$, $1 \mathrm{H}), 2.27-2.44(\mathrm{~m}, 1 \mathrm{H}), 2.69(\mathrm{~s}, 3 \mathrm{H}), 2.80(\mathrm{~d}, J=9.7 \mathrm{~Hz}, 1 \mathrm{H}), 3.08(\mathrm{~s}, 3 \mathrm{H}), 3.14-3.28(\mathrm{~m}$, $5 \mathrm{H}), 3.37-3.55(\mathrm{~m}, 3 \mathrm{H}), 3.92(\mathrm{~s}, 3 \mathrm{H}), 3.98-4.16(\mathrm{~m}, 3 \mathrm{H}), 4.20(\mathrm{dd}, J=15.6,7.6 \mathrm{~Hz}, 7 \mathrm{H}), 4.52$ $(\mathrm{d}, J=12.7 \mathrm{~Hz}, 1 \mathrm{H}), 5.34(\mathrm{~d}, J=6.9 \mathrm{~Hz}, 1 \mathrm{H}), 5.57(\mathrm{dd}, J=14.7,9.0 \mathrm{~Hz}, 1 \mathrm{H}), 5.92(\mathrm{~s}, 1 \mathrm{H}), 6.46$ - $6.72(\mathrm{~m}, 4 \mathrm{H}), 6.88(\mathrm{~s}, 1 \mathrm{H}), 7.17(\mathrm{~s}, 1 \mathrm{H}), 7.33$ (t, $J=7.5 \mathrm{~Hz}, 3 \mathrm{H}), 7.41(\mathrm{t}, J=7.4 \mathrm{~Hz}, 3 \mathrm{H}), 7.60$ $-7.75(\mathrm{~m}, 4 \mathrm{H}), 7.80-7.93(\mathrm{~m}, 4 \mathrm{H}), 8.12(\mathrm{t}, 1 \mathrm{H}), 8.29(\mathrm{~d}, J=6.9 \mathrm{~Hz}, 1 \mathrm{H})$.

Fmoc- $L$-Ala- $D$-Ala- $L$-Ala-NH-CH$-C_{2}-\mathrm{S}-\left(\mathrm{CH}_{2}\right)_{5}$-CO-DM (18c): HRMS $(\mathrm{M}+\mathrm{Na})^{+}$calcd. 1266.5170, found 1266.5170. ${ }^{1} \mathrm{H}$ NMR $(400 \mathrm{MHz}$, DMSO-d6) $\delta 0.71(\mathrm{~s}, 3 \mathrm{H}), 0.96-1.16(\mathrm{~m}$, $10 \mathrm{H}), 1.16-1.51(\mathrm{~m}, 10 \mathrm{H}), 1.52(\mathrm{~s}, 4 \mathrm{H}), 1.82-2.16(\mathrm{~m}, 1 \mathrm{H}), 2.17-2.56(\mathrm{~m}, 11 \mathrm{H}), 2.62(\mathrm{~d}, J=$ 
$5.8 \mathrm{~Hz}, 4 \mathrm{H}), 2.68-2.87(\mathrm{~m}, 3 \mathrm{H}), 2.92-3.04(\mathrm{~m}, 4 \mathrm{H}), 3.09-3.22(\mathrm{~m}, 7 \mathrm{H}), 3.24(\mathrm{~d}, J=7.4 \mathrm{~Hz}$, $1 \mathrm{H}), 3.33-3.50(\mathrm{~m}, 2 \mathrm{H}), 3.73-3.89(\mathrm{~m}, 4 \mathrm{H}), 3.92-4.07(\mathrm{~m}, 2 \mathrm{H}), 4.07-4.25(\mathrm{~m}, 2 \mathrm{H}), 4.45$ $(\mathrm{dd}, J=12.0,2.8 \mathrm{~Hz}, 1 \mathrm{H}), 5.27(\mathrm{q}, J=6.7 \mathrm{~Hz}, 1 \mathrm{H}), 5.40-5.55(\mathrm{~m}, 1 \mathrm{H}), 5.85(\mathrm{~s}, 1 \mathrm{H}), 6.33-$ $6.66(\mathrm{~m}, 4 \mathrm{H}), 6.81(\mathrm{~s}, 2 \mathrm{H}), 7.03-7.19(\mathrm{~m}, 1 \mathrm{H}), 7.19-7.43(\mathrm{~m}, 2 \mathrm{H}), 7.62(\mathrm{~d}, J=11.6 \mathrm{~Hz}, 1 \mathrm{H})$, $7.73-7.85(\mathrm{~m}, 1 \mathrm{H})$.

Fmoc- $\boldsymbol{L}$-Ala- $\boldsymbol{L}$-Ala- $\boldsymbol{D}$-Ala-NH-CH$-\mathrm{C}-\left(\mathrm{CH}_{2}\right)_{5}-\mathrm{CO}-\mathrm{DM}(\mathbf{1 8 d})$ : $\mathrm{HRMS}(\mathrm{M}+\mathrm{Na})^{+}$calcd. 1266.5170, found 1266.5158. ${ }^{1} \mathrm{H}$ NMR (400 MHz, DMSO-d6) $\delta 0.78(\mathrm{~s}, 3 \mathrm{H}), 1.06-1.33(\mathrm{~m}$, $16 \mathrm{H}), 1.44(\mathrm{~d}, J=10.3 \mathrm{~Hz}, 11 \mathrm{H}), 1.59(\mathrm{~s}, 3 \mathrm{H}), 1.99-2.22(\mathrm{~m}, 3 \mathrm{H}), 2.35-2.45(\mathrm{~m}, 2 \mathrm{H}), 2.55(\mathrm{~d}$, $J=1.8 \mathrm{~Hz}, 1 \mathrm{H}), 2.69(\mathrm{~s}, 3 \mathrm{H}), 2.80(\mathrm{~d}, \mathrm{~J}=9.6 \mathrm{~Hz}, 1 \mathrm{H}), 3.08(\mathrm{~s}, 2 \mathrm{H}), 3.25(\mathrm{~s}, 3 \mathrm{H}), 3.39-3.52(\mathrm{~m}$, $3 \mathrm{H}), 3.92(\mathrm{~s}, 3 \mathrm{H}), 3.99-4.40(\mathrm{~m}, 4 \mathrm{H}), 4.52(\mathrm{~d}, J=11.1 \mathrm{~Hz}, 1 \mathrm{H}), 5.34(\mathrm{~d}, J=6.8 \mathrm{~Hz}, 1 \mathrm{H}), 5.57$ $(\mathrm{dd}, J=14.5,9.2 \mathrm{~Hz}, 1 \mathrm{H}), 5.92(\mathrm{~s}, 1 \mathrm{H}), 6.53-6.64(\mathrm{~m}, 2 \mathrm{H}), 6.88(\mathrm{~s}, 2 \mathrm{H}), 7.17(\mathrm{~d}, J=1.9 \mathrm{~Hz}$, $1 \mathrm{H}), 7.33(\mathrm{t}, J=7.3 \mathrm{~Hz}, 3 \mathrm{H}), 7.42(\mathrm{t}, J=7.4 \mathrm{~Hz}, 3 \mathrm{H}), 7.57$ (d, $J=7.4 \mathrm{~Hz}, 1 \mathrm{H}), 7.72(\mathrm{~s}, 3 \mathrm{H}), 7.89$ $(\mathrm{d}, J=7.6 \mathrm{~Hz}, 3 \mathrm{H}), 7.99(\mathrm{~d}, J=7.6 \mathrm{~Hz}, 1 \mathrm{H}), 8.07(\mathrm{~s}, 1 \mathrm{H}), 8.35(\mathrm{~s}, 1 \mathrm{H})$.

Fmoc- $L$-Ala-D-Ala- $L$-Ala-NH-CH$-\mathbf{C}-\left(\mathrm{CH}_{2}\right)_{3}$-CO-DM $(18 \mathrm{e})$ : HRMS $(\mathrm{M}+\mathrm{H})^{+}$calcd. 1216.5038, found 1216.4999. ${ }^{1} \mathrm{H}$ NMR (400 MHz, DMSO-d6) $\delta 0.78(\mathrm{~s}, 3 \mathrm{H}), 0.95-1.29(\mathrm{~m}$, $16 \mathrm{H}), 1.37(\mathrm{~d}, J=3.4 \mathrm{~Hz}, 1 \mathrm{H}), 1.46(\mathrm{t}, J=12.5 \mathrm{~Hz}, 2 \mathrm{H}), 1.59(\mathrm{~s}, 3 \mathrm{H}), 1.62-1.90(\mathrm{~m}, 1 \mathrm{H}), 1.99$ $-2.07(\mathrm{~m}, 1 \mathrm{H}), 2.08(\mathrm{~s}, 2 \mathrm{H}), 2.18-2.43(\mathrm{~m}, 1 \mathrm{H}), 2.50-2.59(\mathrm{~m}, 1 \mathrm{H}), 2.69(\mathrm{~s}, 3 \mathrm{H}), 2.73-2.83$ (m, $1 \mathrm{H}), 3.10(\mathrm{~s}, 2 \mathrm{H}), 3.25(\mathrm{~s}, 3 \mathrm{H}), 3.38-3.55(\mathrm{~m}, 2 \mathrm{H}), 3.91(\mathrm{~s}, 3 \mathrm{H}), 3.99-4.13(\mathrm{~m}, 4 \mathrm{H}), 4.12-$ $4.35(\mathrm{~m}, 7 \mathrm{H}), 4.52(\mathrm{dd}, J=12.0,2.9 \mathrm{~Hz}, 1 \mathrm{H}), 5.34(\mathrm{q}, J=6.7 \mathrm{~Hz}, 1 \mathrm{H}), 5.48-5.65(\mathrm{~m}, 1 \mathrm{H}), 5.92$ (s, $1 \mathrm{H}), 6.48-6.70(\mathrm{~m}, 3 \mathrm{H}), 6.88(\mathrm{~s}, 1 \mathrm{H}), 7.17(\mathrm{~d}, J=1.7 \mathrm{~Hz}, 1 \mathrm{H}), 7.33(\mathrm{t}, J=7.5 \mathrm{~Hz}, 2 \mathrm{H}), 7.41$ (t, $J=7.4 \mathrm{~Hz}, 2 \mathrm{H}), 7.58(\mathrm{~d}, J=7.0 \mathrm{~Hz}, 1 \mathrm{H}), 7.71(\mathrm{t}, J=8.3 \mathrm{~Hz}, 2 \mathrm{H}), 7.89(\mathrm{~d}, J=7.5 \mathrm{~Hz}, 3 \mathrm{H})$, $7.95(\mathrm{~d}, J=7.6 \mathrm{~Hz}, 1 \mathrm{H}), 8.15(\mathrm{~d}, J=7.2 \mathrm{~Hz}, 1 \mathrm{H}), 8.29-8.38(\mathrm{~m}, 1 \mathrm{H}), 8.41(\mathrm{~s}, 1 \mathrm{H})$.

\section{Synthesis of amino-peptide-DM compounds 19a - 19e}

Compounds of the type $\mathrm{H}_{2} \mathrm{~N}$-Peptide-NH- $\mathrm{CH}_{2}-\mathrm{S}-\left(\mathrm{CH}_{2}\right)_{n}-\mathrm{CO}_{2}-\mathrm{DM}$ were prepared as shown for $\mathrm{H}_{2} \mathrm{~N}$ - $L$-Ala- $L$-Ala- $L$-Ala-NH-CH$-\mathrm{CH}_{2}$-S- $\left(\mathrm{CH}_{2}\right)_{5}$-CO-DM.

$\mathbf{H}_{2} \mathbf{N}-L$-Ala- $L$-Ala- $L$-Ala-NH-CH -S-( $\left.\mathbf{C H}_{2}\right)_{5}$-CO-DM (19a): Fmoc- $L$-Ala- $L$-Ala- $L$-Ala-NH$\mathrm{CH}_{2}$-S- $\left(\mathrm{CH}_{2}\right)_{5}$-CO-DM (151 mg, $\left.0.121 \mathrm{mmol}\right)$ was treated with $20 \%$ morpholine in DMF (2 $\mathrm{mL}$ ). The reaction was allowed to proceed with magnetic stirring under argon at room temperature for $1 \mathrm{~h}$. The crude material was purified on a C18, 30 micro, $150 \mathrm{~g}$ column cartridge eluting with deionized water containing $0.1 \%$ formic acid and a linear gradient of acetonitrile from $5 \%$ to $50 \%$ over $26 \mathrm{~min}$. Fractions containing desired product were immediately frozen and lyophilized to give $46 \mathrm{mg}$ ( $37.1 \%$ yield) of a colorless oil. HRMS $(\mathrm{M}+\mathrm{H})^{+}$calcd. 1022.4670; found 1022.4669. ${ }^{1} \mathrm{H}$ NMR (400 MHz, DMSO- $\left.d 6\right) \delta 0.78(\mathrm{~s}, 3 \mathrm{H}), 1.12(\mathrm{~d}, J=6.3$ $\mathrm{Hz}, 3 \mathrm{H}), 1.13-1.21(\mathrm{~m}, 10 \mathrm{H}), 1.21-1.31(\mathrm{~m}, 3 \mathrm{H}), 1.37-1.50(\mathrm{~m}, 4 \mathrm{H}), 1.51-1.57(\mathrm{~m}, 1 \mathrm{H})$, 1.59 (s, 3H), 2.04 (dd, $J=14.4,2.8 \mathrm{~Hz}, 1 \mathrm{H}), 2.15$ (ddd, $J=15.9,8.7,6.0 \mathrm{~Hz}, 1 \mathrm{H}), 2.38$ (td, $J=$ 7.0, $3.6 \mathrm{~Hz}, 2 \mathrm{H}), 2.70(\mathrm{~s}, 3 \mathrm{H}), 2.79(\mathrm{~d}, J=9.6 \mathrm{~Hz}, 1 \mathrm{H}), 3.09(\mathrm{~s}, 3 \mathrm{H}), 3.21(\mathrm{~d}, J=12.5 \mathrm{~Hz}, 1 \mathrm{H})$, 
$3.25(\mathrm{~s}, 3 \mathrm{H}), 3.33-3.55(\mathrm{~m}, 8 \mathrm{H}), 3.93(\mathrm{~s}, 3 \mathrm{H}), 4.01-4.33(\mathrm{~m}, 5 \mathrm{H}), 4.52(\mathrm{dd}, J=12.0,2.8 \mathrm{~Hz}$, $1 \mathrm{H}), 5.34(\mathrm{q}, J=6.7 \mathrm{~Hz}, 1 \mathrm{H}), 5.57(\mathrm{dd}, J=14.6,9.0 \mathrm{~Hz}, 1 \mathrm{H}), 5.95(\mathrm{~s}, 1 \mathrm{H}), 6.48-6.65(\mathrm{~m}, 3 \mathrm{H})$, $6.89(\mathrm{~s}, 1 \mathrm{H}), 7.18(\mathrm{~d}, J=1.8 \mathrm{~Hz}, 1 \mathrm{H}), 8.07(\mathrm{~d}, J=7.5 \mathrm{~Hz}, 1 \mathrm{H}), 8.13(\mathrm{~s}, 1 \mathrm{H}), 8.31(\mathrm{~s}, 1 \mathrm{H}), 8.40(\mathrm{t}$, $J=6.3 \mathrm{~Hz}, 1 \mathrm{H})$.

$\mathbf{H}_{2} \mathbf{N}-\boldsymbol{D}$-Ala- $\boldsymbol{L}$-Ala- $\boldsymbol{L}$-Ala-NH-CH -S- $\left(\mathrm{CH}_{2}\right)_{5}$-CO-DM (19b): HRMS $(\mathrm{M}+\mathrm{H})^{+}$calcd. 1022.4670, found 1022.4675. ${ }^{1} \mathrm{H}$ NMR (400 MHz, DMSO-d6) $\delta 0.71$ (s, 3H), 1.05 (dd, $J=6.7$, $3.1 \mathrm{~Hz}, 7 \mathrm{H}), 1.08-1.16(\mathrm{~m}, 10 \mathrm{H}), 1.19(\mathrm{t}, J=8.1 \mathrm{~Hz}, 3 \mathrm{H}), 1.30-1.50(\mathrm{~m}, 6 \mathrm{H}), 1.52(\mathrm{~s}, 3 \mathrm{H})$, $1.97(\mathrm{~d}, J=13.3 \mathrm{~Hz}, 1 \mathrm{H}), 2.01-2.21(\mathrm{~m}, 2 \mathrm{H}), 2.34(\mathrm{~s}, 3 \mathrm{H}), 2.63(\mathrm{~s}, 3 \mathrm{H}), 2.73(\mathrm{~d}, J=9.8 \mathrm{~Hz}$, $1 \mathrm{H}), 3.02(\mathrm{~s}, 3 \mathrm{H}), 3.14(\mathrm{~d}, J=12.5 \mathrm{~Hz}, 1 \mathrm{H}), 3.33-3.48(\mathrm{~m}, 2 \mathrm{H}), 3.86(\mathrm{~s}, 3 \mathrm{H}), 3.95-4.23(\mathrm{~m}$, $7 \mathrm{H}), 4.45(\mathrm{dd}, J=13.1 \mathrm{~Hz}, 1 \mathrm{H}), 5.27(\mathrm{q}, J=6.8 \mathrm{~Hz}, 1 \mathrm{H}), 5.41-5.58(\mathrm{~m}, 1 \mathrm{H}), 5.85(\mathrm{~s}, 1 \mathrm{H}), 6.39$ $-6.63(\mathrm{~m}, 4 \mathrm{H}), 6.81(\mathrm{~s}, 1 \mathrm{H}), 7.12(\mathrm{~d}, J=1.8 \mathrm{~Hz}, 1 \mathrm{H}), 8.02(\mathrm{~s}, 1 \mathrm{H}), 8.13(\mathrm{~d}, J=7.7 \mathrm{~Hz}, 1 \mathrm{H}), 8.26$ (s, 1H), $8.36(\mathrm{t}, J=6.2 \mathrm{~Hz}, 1 \mathrm{H})$.

$\mathbf{H}_{2} \mathbf{N}-\boldsymbol{L}$-Ala-D-Ala- $\boldsymbol{L}$-Ala-NH-CH$-\mathrm{CH}_{2}-\mathrm{S}-\left(\mathrm{CH}_{2}\right)_{5}$-CO-DM (19c): HRMS $(\mathrm{M}+\mathrm{H})^{+}$calcd. 1022.4670 , found 1022.4680. ${ }^{1} \mathrm{H}$ NMR (400 MHz, DMSO-d6) $\delta 0.71(\mathrm{~s}, 3 \mathrm{H}), 1.01-1.26(\mathrm{~m}, 19 \mathrm{H}), 1.25-$ $1.50(\mathrm{~m}, 6 \mathrm{H}), 1.52(\mathrm{~s}, 3 \mathrm{H}), 1.97(\mathrm{~d}, J=13.7 \mathrm{~Hz}, 1 \mathrm{H}), 2.02-2.22(\mathrm{~m}, 1 \mathrm{H}), 2.35(\mathrm{dd}, J=17.2,9.5$ $\mathrm{Hz}, 2 \mathrm{H}), 2.47(\mathrm{~d}, J=11.5 \mathrm{~Hz}, 1 \mathrm{H}), 2.63(\mathrm{~s}, 4 \mathrm{H}), 2.73(\mathrm{~d}, \mathrm{~J}=9.6 \mathrm{~Hz}, 1 \mathrm{H}), 3.02(\mathrm{~s}, 3 \mathrm{H}), 3.10-$ $3.24(\mathrm{~m}, 6 \mathrm{H}), 3.32-3.50(\mathrm{~m}, 2 \mathrm{H}), 3.86(\mathrm{~s}, 3 \mathrm{H}), 3.95-4.18(\mathrm{~m}, 4 \mathrm{H}), 4.45(\mathrm{dd}, J=12.1,2.6 \mathrm{~Hz}$, $1 \mathrm{H}), 5.27(\mathrm{q}, J=6.9 \mathrm{~Hz}, 1 \mathrm{H}), 5.44-5.55(\mathrm{~m}, 1 \mathrm{H}), 5.85(\mathrm{~s}, 1 \mathrm{H}), 6.42-6.59(\mathrm{~m}, 4 \mathrm{H}), 6.81(\mathrm{~s}$, $1 \mathrm{H}), 7.12(\mathrm{~d}, J=1.7 \mathrm{~Hz}, 1 \mathrm{H}), 8.02(\mathrm{~s}, 1 \mathrm{H}), 8.13(\mathrm{~d}, J=7.7 \mathrm{~Hz}, 1 \mathrm{H}), 8.36(\mathrm{t}, J=6.3 \mathrm{~Hz}, 1 \mathrm{H})$.

$\mathbf{H}_{2} \mathbf{N}$ - $\boldsymbol{L}$-Ala- $\boldsymbol{L}$-Ala-D-Ala-NH-CH -S- $\left(\mathrm{CH}_{2}\right)_{5}$-CO-DM (19d): HRMS $(\mathrm{M}+\mathrm{H})^{+}$calcd. 1022.4670, found 1022.4675. ${ }^{1} \mathrm{H}$ NMR (400 MHz, DMSO-d6) $\delta 0.71(\mathrm{~s}, 3 \mathrm{H}), 0.98-1.14(\mathrm{~m}, 13 \mathrm{H}), 1.14-$ $1.26(\mathrm{~m}, 2 \mathrm{H}), 1.30-1.49(\mathrm{~m}, 4 \mathrm{H}), 1.52(\mathrm{~s}, 3 \mathrm{H}), 2.24-2.41(\mathrm{~m}, 2 \mathrm{H}), 2.44(\mathrm{~d}, J=1.8 \mathrm{~Hz}, 16 \mathrm{H})$, $2.63(\mathrm{~s}, 2 \mathrm{H}), 2.73(\mathrm{~d}, J=9.6 \mathrm{~Hz}, 1 \mathrm{H}), 3.02(\mathrm{~s}, 2 \mathrm{H}), 3.08-3.21(\mathrm{~m}, 4 \mathrm{H}), 3.32-3.49(\mathrm{~m}, 2 \mathrm{H})$, $3.86(\mathrm{~s}, 3 \mathrm{H}), 3.92-4.23(\mathrm{~m}, 3 \mathrm{H}), 4.45(\mathrm{~d}, J=11.8 \mathrm{~Hz}, 1 \mathrm{H}), 5.26(\mathrm{t}, J=6.7 \mathrm{~Hz}, 1 \mathrm{H}), 5.40-5.57$ $(\mathrm{m}, 1 \mathrm{H}), 5.86(\mathrm{~s}, 1 \mathrm{H}), 6.41-6.66(\mathrm{~m}, 3 \mathrm{H}), 6.81(\mathrm{~s}, 1 \mathrm{H}), 7.12(\mathrm{~d}, J=1.7 \mathrm{~Hz}, 1 \mathrm{H}), 8.02(\mathrm{~s}, 1 \mathrm{H})$, $8.10(\mathrm{~d}, J=7.7 \mathrm{~Hz}, 1 \mathrm{H}), 8.35(\mathrm{t}, J=6.3 \mathrm{~Hz}, 1 \mathrm{H})$.

$\mathbf{H}_{2} \mathbf{N}-\boldsymbol{L}$-Ala- $\boldsymbol{D}$-Ala- $\boldsymbol{L}$-Ala-NH-CH -S-( $\left.\mathbf{C H}_{2}\right)_{3}-\mathbf{C O}-\mathrm{DM}(\mathbf{1 9 e})$ : HRMS $(\mathrm{M}+\mathrm{H})^{+}$calcd. 993.4363 , found 993.3826. ${ }^{1} \mathrm{H}$ NMR (400 MHz, DMSO- $\left.d 6\right) \delta 0.77(\mathrm{~s}, 3 \mathrm{H}), 1.12(\mathrm{~d}, J=6.7 \mathrm{~Hz}, 6 \mathrm{H}), 1.17$ $(\mathrm{dd}, J=7.0,5.2 \mathrm{~Hz}, 6 \mathrm{H}), 1.25(\mathrm{~d}, J=13.3 \mathrm{~Hz}, 1 \mathrm{H}), 1.40-1.51(\mathrm{~m}, 2 \mathrm{H}), 1.59(\mathrm{~s}, 3 \mathrm{H}), 2.04(\mathrm{dd}, J$ $=14.4,2.9 \mathrm{~Hz}, 1 \mathrm{H}), 2.41(\mathrm{ddt}, J=18.6,10.1,5.4 \mathrm{~Hz}, 1 \mathrm{H}), 2.61-2.70(\mathrm{~m}, 1 \mathrm{H}), 2.72(\mathrm{~s}, 3 \mathrm{H})$, $2.76-2.90(\mathrm{~m}, 3 \mathrm{H}), 3.09(\mathrm{~s}, 3 \mathrm{H}), 3.20(\mathrm{~d}, J=12.4 \mathrm{~Hz}, 1 \mathrm{H}), 3.25(\mathrm{~s}, 3 \mathrm{H}), 3.33(\mathrm{q}, J=6.9 \mathrm{~Hz}$, $1 \mathrm{H}), 3.39-3.64(\mathrm{~m}, 3 \mathrm{H}), 3.93(\mathrm{~s}, 3 \mathrm{H}), 4.03-4.16(\mathrm{~m}, 2 \mathrm{H}), 4.24(\mathrm{dt}, J=15.1,7.6 \mathrm{~Hz}, 2 \mathrm{H}), 4.53$ $(\mathrm{dd}, J=12.0,2.9 \mathrm{~Hz}, 1 \mathrm{H}), 5.32(\mathrm{q}, J=6.8 \mathrm{~Hz}, 1 \mathrm{H}), 5.51-5.64(\mathrm{~m}, 1 \mathrm{H}), 5.93(\mathrm{~s}, 1 \mathrm{H}), 6.49-$ $6.62(\mathrm{~m}, 2 \mathrm{H}), 6.88(\mathrm{~s}, 1 \mathrm{H}), 7.19(\mathrm{~d}, J=1.8 \mathrm{~Hz}, 1 \mathrm{H}), 8.10(\mathrm{~s}, 1 \mathrm{H}), 8.55(\mathrm{t}, J=6.3 \mathrm{~Hz}, 1 \mathrm{H})$. 


\section{Synthesis of SPDB-peptide-DM compounds 21a - 21e}

Compounds of the type SPDB-Peptide-NH-CH$-\mathrm{S}-\left(\mathrm{CH}_{2}\right)_{n}-\mathrm{CO}_{2}-\mathrm{DM}$ were prepared as shown for SPDB- $L$-Ala- $L$-Ala- $L$-Ala-NH- $\mathrm{CH}_{2}-\mathrm{S}-\left(\mathrm{CH}_{2}\right)_{5}-\mathrm{CO}-\mathrm{DM}$.

SPDB- $L$-Ala- $L$-Ala- $L$-Ala-NH-CH2-S-(CH2)5-CO-DM (21a): $\mathrm{H}_{2} \mathrm{~N}-L$-Ala- $L$-Ala- $L$-Ala-NH$\mathrm{CH}_{2}-\mathrm{S}-\left(\mathrm{CH}_{2}\right)_{5}-\mathrm{CO}-\mathrm{DM}$ (46 mg, $\left.0.045 \mathrm{mmol}\right)$ was dissolved in DMF (2 mL), to which was added succinimidyl 3-(2-pyridyldithio)butanoate (SPDB, $14.7 \mathrm{mg}, 0.045 \mathrm{mmol}$ ) and reacted at room temperature with magnetic stirring under an argon atmosphere for $1 \mathrm{~h}$. The crude material was purified on a $\mathrm{C} 18,430$ micro, $30 \mathrm{~g}$ cartridge eluting with deionized water containing $0.1 \%$ formic acid and a linear gradient of acetonitrile from $5 \%$ to $95 \%$ over $35 \mathrm{~min}$. Fractions containing pure desired product were frozen and lyophilized to give $38 \mathrm{mg}$, (68.5\% yield) of white solid. HRMS $(\mathrm{M}+\mathrm{H})^{+}$calcd. 1233.4796; found 1233.4783. ${ }^{1} \mathrm{H}$ NMR (400 MHz, DMSO- $\left.d 6\right) \delta 0.78(\mathrm{~s}, 3 \mathrm{H})$, $1.12(\mathrm{~d}, J=6.4 \mathrm{~Hz}, 3 \mathrm{H}), 1.14-1.21(\mathrm{~m}, 10 \mathrm{H}), 1.22-1.30(\mathrm{~m}, 3 \mathrm{H}), 1.44(\mathrm{qd}, J=10.2,4.5 \mathrm{~Hz}$, $5 \mathrm{H}), 1.50-1.56(\mathrm{~m}, 1 \mathrm{H}), 1.59(\mathrm{~s}, 3 \mathrm{H}), 1.84(\mathrm{p}, J=7.3 \mathrm{~Hz}, 2 \mathrm{H}), 2.04(\mathrm{dd}, J=14.4,2.7 \mathrm{~Hz}, 1 \mathrm{H})$, 2.15 (ddd, $J=15.8,8.6,5.9 \mathrm{~Hz}, 2 \mathrm{H}), 2.24(\mathrm{t}, J=7.2 \mathrm{~Hz}, 2 \mathrm{H}), 2.39$ (dtdd, $J=18.1,13.2,8.1,4.7$ $\mathrm{Hz}, 3 \mathrm{H}), 2.70$ (s, 3H), $2.76-2.86(\mathrm{~m}, 3 \mathrm{H}), 3.09$ (s, 3H), 3.21 (d, J=12.5 Hz, 1H), 3.25 (s, 3H), $3.43(\mathrm{~d}, J=12.4 \mathrm{~Hz}, 1 \mathrm{H}), 3.48(\mathrm{~d}, J=9.0 \mathrm{~Hz}, 1 \mathrm{H}), 3.92(\mathrm{~s}, 3 \mathrm{H}), 4.13$ (s, 2H), 4.19 (h, $J=6.6 \mathrm{~Hz}$, $4 \mathrm{H}), 4.52(\mathrm{dd}, J=12.1,2.8 \mathrm{~Hz}, 1 \mathrm{H}), 5.34(\mathrm{q}, J=6.8 \mathrm{~Hz}, 1 \mathrm{H}), 5.56(\mathrm{dd}, J=14.7,9.0 \mathrm{~Hz}, 1 \mathrm{H})$, $5.92(\mathrm{~s}, 1 \mathrm{H}), 6.49-6.66(\mathrm{~m}, 3 \mathrm{H}), 6.85-6.97(\mathrm{~m}, 2 \mathrm{H}), 7.18(\mathrm{~d}, J=1.8 \mathrm{~Hz}, 1 \mathrm{H}), 7.23(\mathrm{ddd}, J=$ $7.3,4.8,1.2 \mathrm{~Hz}, 1 \mathrm{H}), 7.76(\mathrm{dt}, J=8.1,1.2 \mathrm{~Hz}, 1 \mathrm{H}), 7.78-7.91(\mathrm{~m}, 2 \mathrm{H}), 8.00(\mathrm{~d}, J=7.1 \mathrm{~Hz}$, $1 \mathrm{H}), 8.09(\mathrm{~d}, J=7.0 \mathrm{~Hz}, 1 \mathrm{H}), 8.33(\mathrm{t}, J=6.3 \mathrm{~Hz}, 1 \mathrm{H}), 8.44(\mathrm{dt}, J=4.7,1.3 \mathrm{~Hz}, 1 \mathrm{H}), 8.50(\mathrm{~s}$, $1 \mathrm{H})$.

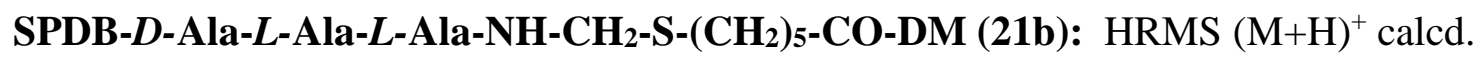
1233.4796, found 1233.4799. ${ }^{1} \mathrm{H}$ NMR (400 MHz, DMSO-d6) $\delta 0.71$ (s, 3H), $1.01-1.22$ (m, $13 \mathrm{H}), 1.27-1.45(\mathrm{~m}, 2 \mathrm{H}), 1.52(\mathrm{~s}, 3 \mathrm{H}), 1.91-2.16(\mathrm{~m}, 1 \mathrm{H}), 2.26(\mathrm{~d}, J=7.4 \mathrm{~Hz}, 7 \mathrm{H}), 2.26(\mathrm{t}, J$ $=1.9 \mathrm{~Hz}, 4 \mathrm{H}), 2.48(\mathrm{t}, J=1.8 \mathrm{~Hz}, 2 \mathrm{H}), 2.57-2.65(\mathrm{~m}, 3 \mathrm{H}), 2.65-2.77(\mathrm{~m}, 2 \mathrm{H}), 3.01(\mathrm{~s}, 2 \mathrm{H})$, $3.13(\mathrm{~d}, J=12.2 \mathrm{~Hz}, 1 \mathrm{H}), 3.18(\mathrm{~s}, 3 \mathrm{H}), 3.32-3.47(\mathrm{~m}, 2 \mathrm{H}), 3.86(\mathrm{~d}, J=6.7 \mathrm{~Hz}, 4 \mathrm{H}), 3.93-4.11$ $(\mathrm{m}, 3 \mathrm{H}), 4.18(\mathrm{t}, J=11.2 \mathrm{~Hz}, 7 \mathrm{H}), 4.39-4.50(\mathrm{~m}, 1 \mathrm{H}), 5.27(\mathrm{~d}, J=6.7 \mathrm{~Hz}, 1 \mathrm{H}), 5.50(\mathrm{dd}, J=$ $14.7,8.8 \mathrm{~Hz}, 1 \mathrm{H}), 5.85(\mathrm{~s}, 1 \mathrm{H}), 6.37-6.61(\mathrm{~m}, 3 \mathrm{H}), 6.81(\mathrm{~s}, 1 \mathrm{H}), 7.11(\mathrm{~d}, J=1.8 \mathrm{~Hz}, 1 \mathrm{H}), 7.26$ $(\mathrm{t}, J=7.4 \mathrm{~Hz}, 2 \mathrm{H}), 7.35(\mathrm{t}, J=7.4 \mathrm{~Hz}, 2 \mathrm{H}), 7.45(\mathrm{~d}, J=7.5 \mathrm{~Hz}, 1 \mathrm{H}), 7.65(\mathrm{t}, J=7.1 \mathrm{~Hz}, 2 \mathrm{H})$, $7.82(\mathrm{~d}, J=7.5 \mathrm{~Hz}, 2 \mathrm{H}), 7.89(\mathrm{~d}, J=7.3 \mathrm{~Hz}, 1 \mathrm{H})$.

SPDB- $\boldsymbol{L}$-Ala-D-Ala- $L-A l a-N H-C H_{2}-\mathrm{S}-\left(\mathrm{CH}_{2}\right)_{5}-\mathrm{CO}-\mathrm{DM}(\mathbf{2 1 c})$ : HRMS (M+H) ${ }^{+}$calcd. 1233.4796, found 1233.4795. ${ }^{1} \mathrm{H}$ NMR (400 MHz, DMSO-d6) $\delta 0.71$ (s, 3H), $1.02-1.25$ (m, $18 \mathrm{H}), 1.29-1.50(\mathrm{~m}, 6 \mathrm{H}), 1.52(\mathrm{~s}, 3 \mathrm{H}), 1.70-1.87(\mathrm{~m}, 2 \mathrm{H}), 1.87-2.14(\mathrm{~m}, 2 \mathrm{H}), 2.13-2.22$ $(\mathrm{m}, 2 \mathrm{H}), 2.27-2.40(\mathrm{~m}, 3 \mathrm{H}), 2.63(\mathrm{~s}, 3 \mathrm{H}), 2.69-2.84(\mathrm{~m}, 4 \mathrm{H}), 3.02(\mathrm{~s}, 3 \mathrm{H}), 3.14(\mathrm{~d}, J=12.3$ $\mathrm{Hz}, 1 \mathrm{H}), 3.18(\mathrm{~s}, 3 \mathrm{H}), 3.32-3.45(\mathrm{~m}, 2 \mathrm{H}), 3.85(\mathrm{~s}, 3 \mathrm{H}), 3.95-4.07$ (m, 2H), $4.07-4.19$ (m, $4 \mathrm{H}), 4.45(\mathrm{dd}, J=11.9,2.7 \mathrm{~Hz}, 1 \mathrm{H}), 5.27(\mathrm{q}, J=6.7 \mathrm{~Hz}, 1 \mathrm{H}), 5.44-5.55(\mathrm{~m}, 1 \mathrm{H}), 5.85(\mathrm{~s}, 1 \mathrm{H})$, $6.42-6.59(\mathrm{~m}, 3 \mathrm{H}), 6.81(\mathrm{~s}, 1 \mathrm{H}), 7.11(\mathrm{~s}, 1 \mathrm{H}), 7.13-7.19(\mathrm{~m}, 1 \mathrm{H}), 7.68(\mathrm{~d}, J=8.2,2.7 \mathrm{~Hz}, 1 \mathrm{H})$, 
$7.72-7.80(\mathrm{~m}, 1 \mathrm{H}), 7.88(\mathrm{t}, J=6.6 \mathrm{~Hz}, 1 \mathrm{H}), 8.04(\mathrm{~d}, J=6.4 \mathrm{~Hz}, 1 \mathrm{H}), 8.09(\mathrm{~d}, J=7.4 \mathrm{~Hz}, 1 \mathrm{H})$, $8.25(\mathrm{t}, J=6.3 \mathrm{~Hz}, 1 \mathrm{H}), 8.37(\mathrm{dd}, J=5.0,1.9 \mathrm{~Hz}, 1 \mathrm{H})$.

SPDB- $\boldsymbol{L}$-Ala- $L-A l a-D-A l a-N H-C H_{2}-S-\left(\mathrm{CH}_{2}\right)_{5}-\mathrm{CO}-\mathrm{DM}(\mathbf{2 1 d})$ : HRMS $(\mathrm{M}+\mathrm{H})^{+}$calcd. 1233.4796, found 1233.4797. ${ }^{1} \mathrm{H}$ NMR (400 MHz, DMSO-d6) $\delta 0.72(\mathrm{~d}, J=3.3 \mathrm{~Hz}, 3 \mathrm{H}), 0.98-$ $1.28(\mathrm{~m}, 22 \mathrm{H}), 1.30-1.46(\mathrm{~m}, 3 \mathrm{H}), 1.53(\mathrm{~s}, 3 \mathrm{H}), 1.78(\mathrm{q}, J=7.1 \mathrm{~Hz}, 2 \mathrm{H}), 1.86-2.16(\mathrm{~m}, 2 \mathrm{H})$, $2.19(\mathrm{q}, J=7.4,5.6 \mathrm{~Hz}, 2 \mathrm{H}), 2.26-2.41(\mathrm{~m}, 2 \mathrm{H}), 2.41-2.55(\mathrm{~m}, 4 \mathrm{H}), 2.64(\mathrm{~d}, J=3.2 \mathrm{~Hz}, 2 \mathrm{H})$, $2.81-2.92(\mathrm{~m}, 1 \mathrm{H}), 3.02(\mathrm{~s}, 2 \mathrm{H}), 3.14(\mathrm{~d}, J=12.0 \mathrm{~Hz}, 1 \mathrm{H}), 3.26(\mathrm{~s}, 1 \mathrm{H}), 3.31-3.48(\mathrm{~m}, 2 \mathrm{H})$, $3.86(\mathrm{~s}, 3 \mathrm{H}), 3.97-4.30(\mathrm{~m}, 7 \mathrm{H}), 4.46(\mathrm{dd}, J=11.8,3.2 \mathrm{~Hz}, 1 \mathrm{H}), 5.24-5.36(\mathrm{~m}, 1 \mathrm{H}), 5.45-$ $5.62(\mathrm{~m}, 1 \mathrm{H}), 5.86(\mathrm{~s}, 1 \mathrm{H}), 6.40-6.65(\mathrm{~m}, 3 \mathrm{H}), 6.82(\mathrm{~d}, J=3.4 \mathrm{~Hz}, 1 \mathrm{H}), 7.11(\mathrm{~d}, J=3.2 \mathrm{~Hz}$, 1H), $7.18(\mathrm{~d}, J=12.1,6.1,4.9 \mathrm{~Hz}, 2 \mathrm{H}), 7.69(\mathrm{~d}, J=8.1 \mathrm{~Hz}, 1 \mathrm{H}), 7.75(\mathrm{t}, J=7.6 \mathrm{~Hz}, 2 \mathrm{H}), 7.89$ $(\mathrm{d}, J=7.8,3.2 \mathrm{~Hz}, 1 \mathrm{H}), 7.95-8.04(\mathrm{~m}, 2 \mathrm{H}), 8.26(\mathrm{~d}, J=6.1 \mathrm{~Hz}, 1 \mathrm{H}), 8.33-8.47(\mathrm{~m}, 1 \mathrm{H})$.

SPDB- $\boldsymbol{L}$-Ala- $\boldsymbol{D}$-Ala- $\boldsymbol{L}$-Ala-NH-CH2-S-(CH$)_{3}-\mathrm{CO}-\mathrm{CM}(21 \mathrm{e}): \mathrm{HRMS}(\mathrm{M}+\mathrm{H})^{+}$calcd. 1205.4488, found 1205.4315. ${ }^{1} \mathrm{H}$ NMR (400 MHz, DMSO-d6) $\delta 0.71$ (s, 3H), $0.94-1.24$ (m, $20 \mathrm{H}), 1.38(\mathrm{~s}, 3 \mathrm{H}), 1.52(\mathrm{~s}, 3 \mathrm{H}), 1.57-1.87(\mathrm{~m}, 1 \mathrm{H}), 1.89-2.08(\mathrm{~m}, 1 \mathrm{H}), 2.26(\mathrm{t}, J=15.1 \mathrm{~Hz}$, $1 \mathrm{H}), 2.50(\mathrm{~d}, J=5.2 \mathrm{~Hz}, 2 \mathrm{H}), 2.54-2.79(\mathrm{~m}, 7 \mathrm{H}), 3.05(\mathrm{~d}, J=3.8 \mathrm{~Hz}, 3 \mathrm{H}), 3.18(\mathrm{~s}, 5 \mathrm{H}), 3.29-$ $3.46(\mathrm{~m}, 3 \mathrm{H}), 3.86(\mathrm{~d}, J=6.1 \mathrm{~Hz}, 4 \mathrm{H}), 4.00(\mathrm{~s}, 3 \mathrm{H}), 4.05-4.24(\mathrm{~m}, 4 \mathrm{H}), 4.33-4.54(\mathrm{~m}, 1 \mathrm{H})$, $5.17-5.38(\mathrm{~m}, 1 \mathrm{H}), 5.39-5.58(\mathrm{~m}, 1 \mathrm{H}), 5.85(\mathrm{~s}, 1 \mathrm{H}), 6.29-6.58(\mathrm{~m}, 4 \mathrm{H}), 6.63(\mathrm{~s}, 1 \mathrm{H}), 6.81(\mathrm{~s}$, $1 \mathrm{H}), 7.04-7.19(\mathrm{~m}, 1 \mathrm{H}), 7.90(\mathrm{~s}, 1 \mathrm{H}), 8.14-8.39(\mathrm{~m}, 1 \mathrm{H}), 8.45(\mathrm{~s}, 1 \mathrm{H})$.

\section{Synthesis of thio-peptide-DM compounds $22 \mathrm{a}-22 \mathrm{e}$}

Compounds of the type HS- $\left(\mathrm{CH}_{2}\right)_{3} \mathrm{CO}-\mathrm{Peptide}-\mathrm{NH}-\mathrm{CH}_{2}-\mathrm{S}-\left(\mathrm{CH}_{2}\right)_{\mathrm{n}}-\mathrm{CO}_{2}-\mathrm{DM}$ were prepared as shown for $\mathrm{HS}-\left(\mathrm{CH}_{2}\right)_{3} \mathrm{CO}-L-\mathrm{Ala}-L-\mathrm{Ala}-\mathrm{L}-\mathrm{Ala}-\mathrm{NH}-\mathrm{CH}_{2}-\mathrm{S}-\left(\mathrm{CH}_{2}\right)_{5}-\mathrm{CO}-\mathrm{DM}$.

HS- $\left(\mathrm{CH}_{2}\right)_{3} \mathrm{CO}-L-A l a-L-A l a-L-A l a-N H-C H 2-S-\left(\mathrm{CH}_{2}\right)$ 5-CO-DM (22a): SPDB- $L-A l a-L-A l a-L$ Ala-NH-CH $2-S-\left(\mathrm{CH}_{2}\right)_{5}-\mathrm{CO}-\mathrm{DM}(38 \mathrm{mg}, 0.031 \mathrm{mmol})$ was dissolved in DMSO (1 mL) to which a solution of DTT $(19 \mathrm{mg}, 0.12 \mathrm{mmol})$ in $100 \mathrm{mM}$ potassium phosphate, $2 \mathrm{mM}$ EDTA $\mathrm{pH} 7.5$ buffer $(1 \mathrm{~mL})$ was added. The reaction was allowed to proceed at room temperature with magnetic stirring under argon for $1 \mathrm{~h}$. The crude reaction was purified on a C18, 30 micron, 30g cartridge eluting with deionized water containing $0.1 \%$ formic acid and a linear gradient of acetonitrile of $5 \%$ to $95 \%$ over 35 min. Fractions containing desired product were immediately frozen and lyophilized to give $18.2 \mathrm{mg}$, (52.5\% yield) of a white solid. HRMS $(\mathrm{M}+\mathrm{H})+$ calcd. 1124.4809; found 1124.4798. ${ }^{1} \mathrm{H}$ NMR (400 MHz, DMSO-d6) $\delta 0.78(\mathrm{~s}, 3 \mathrm{H}), 1.12$ (d, J=6.4 $\mathrm{Hz}, 3 \mathrm{H}), 1.14-1.21(\mathrm{~m}, 10 \mathrm{H}), 1.22-1.30(\mathrm{~m}, 3 \mathrm{H}), 1.37-1.50(\mathrm{~m}, 5 \mathrm{H}), 1.51-1.57(\mathrm{~m}, 1 \mathrm{H})$, $1.59(\mathrm{~s}, 3 \mathrm{H}), 1.74(\mathrm{p}, J=7.2 \mathrm{~Hz}, 2 \mathrm{H}), 2.04(\mathrm{dd}, J=14.4,2.8 \mathrm{~Hz}, 1 \mathrm{H}), 2.09-2.18(\mathrm{~m}, 1 \mathrm{H}), 2.18$ $-2.24(\mathrm{~m}, 2 \mathrm{H}), 2.27(\mathrm{t}, J=7.6 \mathrm{~Hz}, 1 \mathrm{H}), 2.38(\mathrm{td}, J=7.1,4.7 \mathrm{~Hz}, 2 \mathrm{H}), 2.44(\mathrm{t}, J=7.3 \mathrm{~Hz}, 2 \mathrm{H})$, 
2.70 (s, 3H), 2.79 (d, $J=9.6 \mathrm{~Hz}, 1 \mathrm{H}), 3.09$ (s, 3H), $3.21(\mathrm{~d}, J=12.6 \mathrm{~Hz}, 1 \mathrm{H}), 3.25(\mathrm{~s}, 3 \mathrm{H}), 3.43$ (d, $J=12.4 \mathrm{~Hz}, 1 \mathrm{H}), 3.49$ (d, $J=9.0 \mathrm{~Hz}, 1 \mathrm{H}), 3.93(\mathrm{~s}, 3 \mathrm{H}), 4.08$ (ddd, $J=21.6,11.4,4.1 \mathrm{~Hz}$, $2 \mathrm{H}), 4.13-4.28(\mathrm{~m}, 4 \mathrm{H}), 4.52(\mathrm{dd}, J=12.1,2.8 \mathrm{~Hz}, 1 \mathrm{H}), 5.34(\mathrm{q}, J=6.7 \mathrm{~Hz}, 1 \mathrm{H}), 5.56(\mathrm{dd}, J=$ 14.7, $9.0 \mathrm{~Hz}, 1 \mathrm{H}), 5.91(\mathrm{~d}, J=1.4 \mathrm{~Hz}, 1 \mathrm{H}), 6.48-6.66(\mathrm{~m}, 3 \mathrm{H}), 6.88(\mathrm{~s}, 1 \mathrm{H}), 7.18(\mathrm{~d}, J=1.8 \mathrm{~Hz}$, $1 \mathrm{H}), 7.86(\mathrm{~d}, J=7.5 \mathrm{~Hz}, 1 \mathrm{H}), 7.96(\mathrm{~d}, J=7.3 \mathrm{~Hz}, 1 \mathrm{H}), 8.05(\mathrm{~d}, J=7.1 \mathrm{~Hz}, 1 \mathrm{H}), 8.33(\mathrm{t}, J=6.3$ $\mathrm{Hz}, 1 \mathrm{H})$.

HS- $\left(\mathrm{CH}_{2}\right)_{3}$ CO-D-Ala- $L$-Ala- $\boldsymbol{L}$-Ala-NH- $\mathrm{CH}_{2}-\mathrm{S}-\left(\mathrm{CH}_{2}\right)_{5}-\mathrm{CO}-\mathrm{DM}(\mathbf{2 2 b})$ : HRMS (M+Na) ${ }^{+}$calcd. 1146.4629, found 1146.4591. ${ }^{1} \mathrm{H}$ NMR (400 MHz, DMSO-d6) $\delta 0.71(\mathrm{~s}, 3 \mathrm{H}), 1.03-1.25$ (m, $19 \mathrm{H}), 1.30-1.45(\mathrm{~m}, 6 \mathrm{H}), 1.52(\mathrm{~s}, 4 \mathrm{H}), 1.65(\mathrm{p}, J=7.3 \mathrm{~Hz}, 2 \mathrm{H}), 1.91-2.02(\mathrm{~m}, 1 \mathrm{H}), 2.02-$ $2.13(\mathrm{~m}, 1 \mathrm{H}), 2.12-2.19(\mathrm{~m}, 4 \mathrm{H}), 2.29-2.39(\mathrm{~m}, 4 \mathrm{H}), 2.63(\mathrm{~s}, 3 \mathrm{H}), 2.73(\mathrm{~d}, J=9.6 \mathrm{~Hz}, 1 \mathrm{H})$, $3.02(\mathrm{~s}, 3 \mathrm{H}), 3.14(\mathrm{~d}, J=12.5 \mathrm{~Hz}, 1 \mathrm{H}), 3.33-3.47$ (m, 2H), 3.86 (s, 3H), 4.01 (td, $J=10.4,9.7$, $4.3 \mathrm{~Hz}, 2 \mathrm{H}), 4.04-4.16(\mathrm{~m}, 5 \mathrm{H}), 4.45$ (dd, $J=12.0,2.9 \mathrm{~Hz}, 1 \mathrm{H}), 5.27$ (q, $J=6.7 \mathrm{~Hz}, 1 \mathrm{H}), 5.43$ $-5.56(\mathrm{~m}, 1 \mathrm{H}), 5.85(\mathrm{~s}, 1 \mathrm{H}), 6.38-6.61(\mathrm{~m}, 4 \mathrm{H}), 6.81(\mathrm{~s}, 1 \mathrm{H}), 7.11(\mathrm{~d}, J=1.8 \mathrm{~Hz}, 1 \mathrm{H}), 7.82(\mathrm{~d}$, $J=7.7 \mathrm{~Hz}, 1 \mathrm{H}), 7.97(\mathrm{t}, J=6.3 \mathrm{~Hz}, 1 \mathrm{H}), 8.10(\mathrm{~d}, J=6.0 \mathrm{~Hz}, 1 \mathrm{H}), 8.25(\mathrm{~d}, J=6.9 \mathrm{~Hz}, 1 \mathrm{H})$.

HS- $\left(\mathrm{CH}_{2}\right)_{3}$ CO- $\boldsymbol{L}$-Ala- $\boldsymbol{D}$-Ala- $\boldsymbol{L}$-Ala-NH- $\mathrm{CH}_{2}-\mathrm{S}-\left(\mathrm{CH}_{2}\right)_{5}-\mathrm{CO}-\mathrm{DM}(\mathbf{2 2 c})$ : HRMS (M+Na) ${ }^{+}$calcd. 1146.4629, found 1146.4553. ${ }^{1} \mathrm{H}$ NMR (400 MHz, DMSO-d6) $\delta 0.71(\mathrm{~s}, 3 \mathrm{H}), 0.99-1.26(\mathrm{~m}$, $21 \mathrm{H}), 1.31-1.45(\mathrm{~m}, 5 \mathrm{H}), 1.52$ (s, 3H), 1.67 (p, $J=7.2 \mathrm{~Hz}, 2 \mathrm{H}), 1.89-2.02(\mathrm{~m}, 1 \mathrm{H}), 2.02-$ $2.24(\mathrm{~m}, 4 \mathrm{H}), 2.25-2.46(\mathrm{~m}, 3 \mathrm{H}), 2.63(\mathrm{~s}, 3 \mathrm{H}), 2.73(\mathrm{~d}, J=9.7 \mathrm{~Hz}, 1 \mathrm{H}), 3.02(\mathrm{~s}, 3 \mathrm{H}), 3.18(\mathrm{~s}$, $3 \mathrm{H}), 3.32-3.51(\mathrm{~m}, 2 \mathrm{H}), 3.86(\mathrm{~s}, 3 \mathrm{H}), 3.96-4.18(\mathrm{~m}, 7 \mathrm{H}), 4.45(\mathrm{dd}, J=12.0,2.9 \mathrm{~Hz}, 1 \mathrm{H}), 5.27$ $(\mathrm{q}, \mathrm{J}=6.8 \mathrm{~Hz}, 1 \mathrm{H}), 5.44-5.63(\mathrm{~m}, 1 \mathrm{H}), 5.85(\mathrm{~s}, 1 \mathrm{H}), 6.37-6.59(\mathrm{~m}, 4 \mathrm{H}), 6.81(\mathrm{~s}, 1 \mathrm{H}), 7.11(\mathrm{~d}$, $J=1.8 \mathrm{~Hz}, 1 \mathrm{H}), 7.89(\mathrm{~d}, J=7.7 \mathrm{~Hz}, 1 \mathrm{H}), 8.03(\mathrm{~d}, J=6.5 \mathrm{~Hz}, 1 \mathrm{H}), 8.08(\mathrm{~d}, J=7.3 \mathrm{~Hz}, 1 \mathrm{H}), 8.27$ (t, $J=6.3 \mathrm{~Hz}, 1 \mathrm{H})$.

HS- $\left(\mathrm{CH}_{2}\right)_{3}$ CO- $\boldsymbol{L}$-Ala- $L$-Ala-D-Ala-NH-CH$-\mathrm{CH}-\left(\mathrm{CH}_{2}\right)_{5}$-CO-DM (22d): HRMS (M+Na) ${ }^{+}$calcd. 1146.4629, found 1146.4519. ${ }^{1} \mathrm{H}$ NMR (400 MHz, DMSO-d6) $\delta 0.71(\mathrm{~s}, 3 \mathrm{H}), 0.95-1.24(\mathrm{~m}$, 20H), $1.27-1.45(\mathrm{~m}, 5 \mathrm{H}), 1.52(\mathrm{~s}, 3 \mathrm{H}), 1.67(\mathrm{p}, J=7.3 \mathrm{~Hz}, 2 \mathrm{H}), 1.93-2.01(\mathrm{~m}, 1 \mathrm{H}), 2.02-$ $2.22(\mathrm{~m}, 4 \mathrm{H}), 2.22-2.41(\mathrm{~m}, 5 \mathrm{H}), 2.63(\mathrm{~s}, 3 \mathrm{H}), 2.73(\mathrm{~d}, J=9.6 \mathrm{~Hz}, 1 \mathrm{H}), 3.02(\mathrm{~s}, 3 \mathrm{H}), 3.18(\mathrm{~s}$, $4 \mathrm{H}), 3.39(\mathrm{dd}, J=21.4,10.7 \mathrm{~Hz}, 2 \mathrm{H}), 3.86(\mathrm{~s}, 3 \mathrm{H}), 3.94-4.24(\mathrm{~m}, 6 \mathrm{H}), 4.45(\mathrm{dd}, J=12.0,2.8$ $\mathrm{Hz}, 1 \mathrm{H}), 5.27(\mathrm{q}, J=6.7 \mathrm{~Hz}, 1 \mathrm{H}), 5.44-5.57(\mathrm{~m}, 1 \mathrm{H}), 5.85(\mathrm{~s}, 1 \mathrm{H}), 6.37-6.65(\mathrm{~m}, 3 \mathrm{H}), 6.81(\mathrm{~s}$, $1 \mathrm{H}), 7.11(\mathrm{~d}, J=1.8 \mathrm{~Hz}, 1 \mathrm{H}), 7.89(\mathrm{~d}, J=7.6 \mathrm{~Hz}, 1 \mathrm{H}), 7.93-8.05(\mathrm{~m}, 2 \mathrm{H}), 8.26(\mathrm{t}, J=6.4 \mathrm{~Hz}$, $1 \mathrm{H})$.

HS- $\left(\mathrm{CH}_{2}\right)_{3}$ CO- $L$-Ala-D-Ala- $\boldsymbol{L}$-Ala-NH-CH $2-\mathrm{S}-\left(\mathrm{CH}_{2}\right)_{3}$-CO-DM (22e): HRMS (M+H) ${ }^{+}$calcd. 1096.4496, found 1096.4464. 1H NMR (400 MHz, DMSO- $d 6) \delta 0.78(\mathrm{~s}, 3 \mathrm{H}), 1.02-1.31(\mathrm{~m}$, $19 \mathrm{H}), 1.35-1.55$ (m, 2H), 1.60 (s, 3H), 1.74 (p, J=7.4 Hz, 3H), $1.78-1.93$ (m, 1H), $2.14-$ $2.33(\mathrm{~m}, 4 \mathrm{H}), 2.41-2.49(\mathrm{~m}, 2 \mathrm{H}), 2.71(\mathrm{~s}, 3 \mathrm{H}), 2.80(\mathrm{~d}, J=9.6 \mathrm{~Hz}, 1 \mathrm{H}), 3.12(\mathrm{~s}, 3 \mathrm{H}), 3.22(\mathrm{~d}, J$ $=12.7 \mathrm{~Hz}, 1 \mathrm{H}), 3.26(\mathrm{~s}, 3 \mathrm{H}), 3.47(\mathrm{dd}, J=21.3,10.6 \mathrm{~Hz}, 2 \mathrm{H}), 3.93(\mathrm{~s}, 4 \mathrm{H}), 4.03-4.13(\mathrm{~m}, 3 \mathrm{H})$, $4.13-4.25(\mathrm{~m}, 3 \mathrm{H}), 4.52(\mathrm{dd}, J=12.0,2.8 \mathrm{~Hz}, 1 \mathrm{H}), 5.35(\mathrm{q}, J=6.8 \mathrm{~Hz}, 1 \mathrm{H}), 5.50-5.64(\mathrm{~m}$, $1 \mathrm{H}), 5.92(\mathrm{~s}, 1 \mathrm{H}), 6.47-6.69(\mathrm{~m}, 4 \mathrm{H}), 6.88(\mathrm{~s}, 1 \mathrm{H}), 7.18(\mathrm{~d}, J=1.7 \mathrm{~Hz}, 1 \mathrm{H}), 7.94(\mathrm{~d}, J=7.3 \mathrm{~Hz}$, $1 \mathrm{H}), 8.09(\mathrm{~d}, J=6.4 \mathrm{~Hz}, 1 \mathrm{H}), 8.15(\mathrm{~d}, J=7.3 \mathrm{~Hz}, 1 \mathrm{H}), 8.32(\mathrm{t}, J=6.3 \mathrm{~Hz}, 1 \mathrm{H})$. 


\section{Synthesis of immolative ADC metabolites}

Metabolites 12a and 12b of the immolative ADCs were synthesized as depicted in Figure S 3 . Compound 11a was prepared by reacting DM-H (14) with 6-mercaptohexanoic acid and EDC. S-methylation of 10a with iodomethane gave (12a). DM-H was also reacted with SPDB to give (24). Reduction of $\mathbf{2 4}$ with 1, 4-dithiothreitol (DTT) gave 11b, which was reacted with iodomethane to give $\mathbf{1 2 b}$.

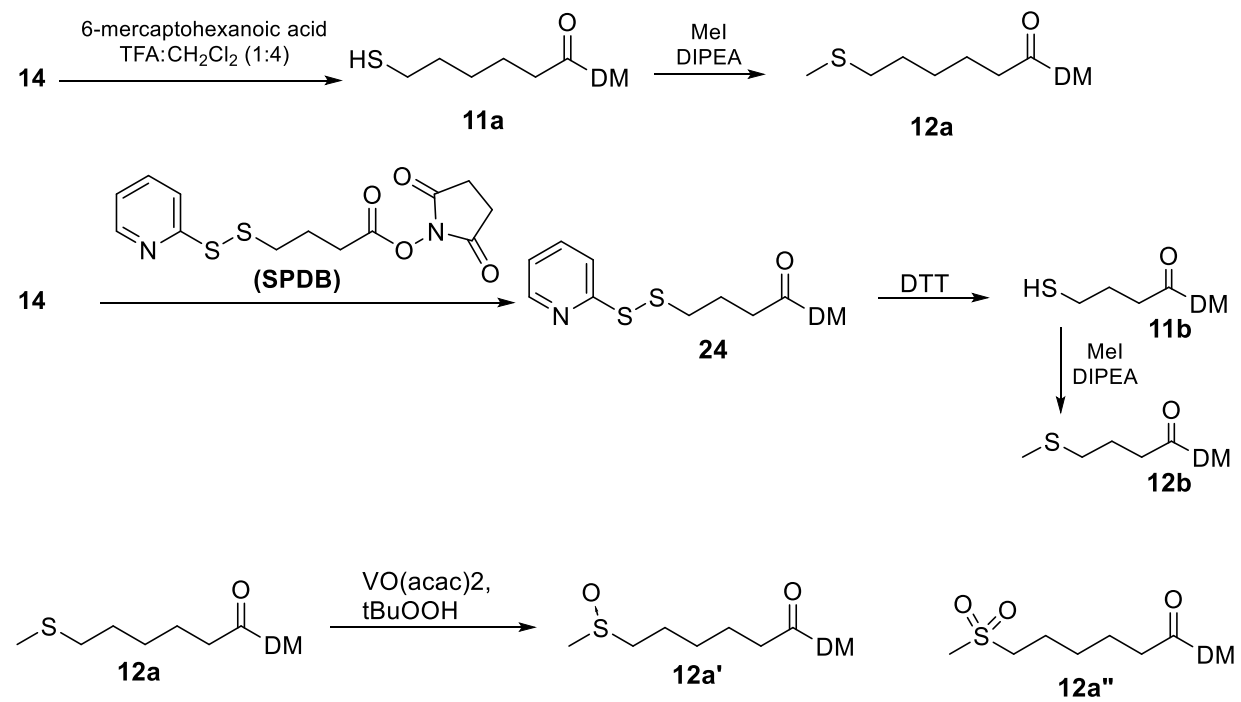

Figure S 3 Preparation of the immolative ADC metabolites 12a, 12b, 12c, 12a' and 12a"

DM-CO-(CH2)5-SH (11a): To DM-H stock solution (1.5 mL, $0.100 \mathrm{mmol})$, was added EDC (29 $\mathrm{mg}, 0.150 \mathrm{mmol})$ and DIPEA $(17.5 \mu \mathrm{L}, 0.100 \mathrm{mmol})$ with magnetic stirring at room temperature for $10 \mathrm{~min}$. Then 6-mercaptohexanoic acid $(13.8 \mu \mathrm{L}, 0.100 \mathrm{mmol})$ was added. After $30 \mathrm{~min}$ the crude material was purified via semi-prep HPLC using a XDB-C18, 21.2 x 5 mm, $5 \mu \mathrm{m}$ eluting with deionized water containing $0.1 \%$ formic acid and a linear gradient of acetonitrile from $5 \%$ to $95 \%$ over $30 \mathrm{~min}$ at $20 \mathrm{ml} / \mathrm{min}$. Fractions containing desired product were immediately combined and frozen then lyophilized to give $12 \mathrm{mg}(15 \%$ yield $)$ of white solid. HRMS $(\mathrm{M}+\mathrm{H})^{+}$ calcd. 780.3291, found 780.3281. ${ }^{1} \mathrm{H}$ NMR (400 MHz, DMSO-d6) $\delta 0.79$ (s, 3H), $1.06-1.21$ $(\mathrm{m}, 5 \mathrm{H}), 1.21-1.57(\mathrm{~m}, 6 \mathrm{H}), 1.60(\mathrm{~s}, 2 \mathrm{H}), 2.00-2.12(\mathrm{~m}, 2 \mathrm{H}), 2.12-2.27(\mathrm{~m}, 2 \mathrm{H}), 2.27-2.37$ (m, 2H), $2.50(\mathrm{~s}, 4 \mathrm{H}), 2.70(\mathrm{~s}, 3 \mathrm{H}), 2.74-2.91(\mathrm{~m}, 2 \mathrm{H}), 2.91-3.09(\mathrm{~m}, 1 \mathrm{H}), 3.10(\mathrm{~s}, 2 \mathrm{H}), 3.19-$ $3.24(\mathrm{~m}, 2 \mathrm{H}), 3.26(\mathrm{~s}, 3 \mathrm{H}), 3.39-3.53(\mathrm{~m}, 2 \mathrm{H}), 3.94(\mathrm{~s}, 3 \mathrm{H}), 4.03-4.11(\mathrm{~m}, 1 \mathrm{H}), 4.52(\mathrm{dd}, J=$ $12.0,2.9 \mathrm{~Hz}, 1 \mathrm{H}), 5.35(\mathrm{q}, J=6.8 \mathrm{~Hz}, 1 \mathrm{H}), 5.52-5.62(\mathrm{~m}, 1 \mathrm{H}), 5.93(\mathrm{~d}, J=1.3 \mathrm{~Hz}, 1 \mathrm{H}), 6.49-$ $6.67(\mathrm{~m}, 3 \mathrm{H}), 6.89$ (s, 1H), 7.20 (d, $J=1.8 \mathrm{~Hz}, 1 \mathrm{H})$. 
DM-CO-( $\left.\mathbf{C H}_{2}\right)_{5}-\mathrm{SMe}$ (12a): DM-CO- $\left(\mathrm{CH}_{2}\right)_{5}-\mathrm{SH}(12 \mathrm{mg}, 0.015 \mathrm{mmol})$ was dissolved in DMF $(2 \mathrm{~mL})$, treated with DIPEA $(24 \mu \mathrm{L}, 0.139 \mathrm{mmol})$ and iodomethane $(2.88 \mu \mathrm{L}, 0.046 \mathrm{mmol})$ was allowed to proceed under argon at room temperature for $2 \mathrm{~h}$. The crude material was purified via a XDB-C18, $21.2 \times 5 \mathrm{~mm}, 5 \mu \mathrm{m}$ column with a flow rate $20 \mathrm{ml} / \mathrm{min}$. Using deionized water with $0.1 \%$ formic acid and linear gradient of acetonitrile from $5 \%$ to $95 \%$ over $30 \mathrm{~min}$ at $20 \mathrm{ml} / \mathrm{min}$. Fractions containing desired product were combined, frozen then lyophilized to give $2 \mathrm{mg}$ (16\% yield) of white solid. HRMS $(\mathrm{M}+\mathrm{H})^{+}$calcd. 794.3448, found 794.3440. ${ }^{1} \mathrm{H}$ NMR $(400 \mathrm{MHz}$, DMSO-d6) $\delta 0.71(\mathrm{~s}, 3 \mathrm{H}), 1.01-1.13(\mathrm{~m}, 6 \mathrm{H}), 1.13-1.27(\mathrm{~m}, 3 \mathrm{H}), 1.27-1.50(\mathrm{~m}, 6 \mathrm{H}), 1.53$ (s, 3H), $1.87(\mathrm{~s}, 2 \mathrm{H}), 1.93-2.04(\mathrm{~m}, 2 \mathrm{H}), 2.04-2.15(\mathrm{~m}, 1 \mathrm{H}), 2.15-2.27(\mathrm{~m}, 2 \mathrm{H}), 2.27-2.41$ (m, 1H), $2.63(\mathrm{~s}, 3 \mathrm{H}), 2.73(\mathrm{~d}, J=9.6 \mathrm{~Hz}, 1 \mathrm{H}), 3.02(\mathrm{~s}, 3 \mathrm{H}), 3.10-3.22(\mathrm{~m}, 5 \mathrm{H}), 3.33-3.49(\mathrm{~m}$, 2H), $3.86(\mathrm{~s}, 3 \mathrm{H}), 3.94-4.06(\mathrm{~m}, 1 \mathrm{H}), 4.45(\mathrm{dd}, J=12.1,2.8 \mathrm{~Hz}, 1 \mathrm{H}), 5.28(\mathrm{q}, J=6.7 \mathrm{~Hz}, 1 \mathrm{H})$, $5.44-5.56(\mathrm{~m}, 1 \mathrm{H}), 5.85(\mathrm{~s}, 1 \mathrm{H}), 6.42-6.62(\mathrm{~m}, 3 \mathrm{H}), 6.81(\mathrm{~s}, 1 \mathrm{H}), 7.13(\mathrm{~d}, J=1.7 \mathrm{~Hz}, 1 \mathrm{H})$.

DM-CO-(CH2)3-SSPy (24): succinimidyl 3-(2-pyridyldithio)butanoate (SPDB, $30.1 \mathrm{mg}, 0.092$ $\mathrm{mmol}$ ) was added to DM-H (5) stock solution $(0.81 \mathrm{~mL}, 0.046 \mathrm{mmol})$ at room temperature with magnetic stirring. After $30 \mathrm{~min}$. the solution was purified on a XDB-C18, $21.2 \times 5 \mathrm{~mm}, 5 \mu \mathrm{m}$ column with a flow rate $20 \mathrm{ml} / \mathrm{min}$. Using deionized water with $0.1 \%$ formic acid and linear gradient of acetonitrile from $5 \%$ to $95 \%$ over $30 \mathrm{~min}$ at $20 \mathrm{ml} / \mathrm{min}$. Fractions containing desired product were combined, frozen then lyophilized to give $6 \mathrm{mg}$ ( $15 \%$ yield) of a white solid. HRMS $(\mathrm{M}+\mathrm{H})^{+}$calcd. 861.2964, found 861.2963. ${ }^{1} \mathrm{H}$ NMR (400 MHz, DMSO- $\left.d 6\right) \delta 0.70(\mathrm{~s}$, $3 \mathrm{H}), 1.02-1.12(\mathrm{~m}, 7 \mathrm{H}), 1.13-1.21(\mathrm{~m}, 1 \mathrm{H}), 1.31-1.45(\mathrm{~m}, 3 \mathrm{H}), 1.52(\mathrm{~s}, 3 \mathrm{H}), 1.70-1.90(\mathrm{~m}$, $2 \mathrm{H}), 1.96(\mathrm{dd}, J=14.2,2.9 \mathrm{~Hz}, 1 \mathrm{H}), 2.19-2.31(\mathrm{~m}, 1 \mathrm{H}), 2.62(\mathrm{~s}, 3 \mathrm{H}), 2.68-2.81(\mathrm{~m}, 4 \mathrm{H}), 3.00$ (s, 2H), $3.18(\mathrm{~s}, 4 \mathrm{H}), 3.34(\mathrm{~d}, J=12.4 \mathrm{~Hz}, 1 \mathrm{H}), 3.41(\mathrm{~d}, J=9.1 \mathrm{~Hz}, 1 \mathrm{H}), 3.87(\mathrm{~s}, 3 \mathrm{H}), 4.00(\mathrm{t}, J=$ $11.2 \mathrm{~Hz}, 1 \mathrm{H}), 4.44$ (dd, $J=12.0,2.9 \mathrm{~Hz}, 1 \mathrm{H}), 5.25(\mathrm{q}, J=6.8 \mathrm{~Hz}, 1 \mathrm{H}), 5.41-5.52(\mathrm{~m}, 1 \mathrm{H}), 5.85$ (s, 1H), $6.43-6.53(\mathrm{~m}, 3 \mathrm{H}), 6.81(\mathrm{~s}, 1 \mathrm{H}), 7.09(\mathrm{~d}, J=1.8 \mathrm{~Hz}, 1 \mathrm{H}), 7.12-7.19(\mathrm{~m}, 1 \mathrm{H}), 7.50-$ $7.61(\mathrm{~m}, 1 \mathrm{H}), 7.66-7.76(\mathrm{~m}, 1 \mathrm{H}), 8.31-8.39(\mathrm{~m}, 1 \mathrm{H})$.

DM-CO-(CH2)3-SH (11b): DM-CO- $\left(\mathrm{CH}_{2}\right)_{3}$-SSPy $(6 \mathrm{mg}, 6.96 \mu \mathrm{mol})$ was added to a solution of DTT $(1.1 \mathrm{mg}, 6.96 \mu \mathrm{mol})$ in 2:1 DMSO: potassium phosphate $2 \mathrm{mM}$ EDTA pH 7.5 buffer $(0.5$ $\mathrm{mL}$ ) and magnetically stirred at room temperature for $20 \mathrm{~min}$. Crude solution was purified on a XDB-C18, $21.2 \times 5 \mathrm{~mm}, 5 \mu \mathrm{m}$ column with a flow rate $20 \mathrm{ml} / \mathrm{min}$. Using deionized water with $0.1 \%$ formic acid and linear gradient of acetonitrile from 5\% to $95 \%$ over $30 \mathrm{~min}$ at $20 \mathrm{ml} / \mathrm{min}$. Fractions containing desired product were combined, frozen then lyophilized to give $5 \mathrm{mg}$ ( $95 \%$ yield) of white solid. HRMS $(\mathrm{M}+\mathrm{H})^{+}$calcd. 752.2978, found 752.2962. ${ }^{1} \mathrm{H}$ NMR $(400 \mathrm{MHz}$, DMSO-d6) $\delta 0.71(\mathrm{~d}, J=1.9 \mathrm{~Hz}, 3 \mathrm{H}), 1.08(\mathrm{dd}, J=18.6,6.6 \mathrm{~Hz}, 7 \mathrm{H}), 1.18(\mathrm{~d}, J=12.4 \mathrm{~Hz}, 2 \mathrm{H})$, $1.27-1.49(\mathrm{~m}, 3 \mathrm{H}), 1.52(\mathrm{~d}, J=2.7 \mathrm{~Hz}, 4 \mathrm{H}), 1.55-1.68(\mathrm{~m}, 1 \mathrm{H}), 1.77(J=14.2,8.5,6.5 \mathrm{~Hz}$, $1 \mathrm{H}), 1.91-2.05(\mathrm{~m}, 1 \mathrm{H}), 2.15(\mathrm{t}, J=7.9 \mathrm{~Hz}, 1 \mathrm{H}), 2.38(\mathrm{~s}, 2 \mathrm{H}), 2.44-2.60(\mathrm{~m}, 1 \mathrm{H}), 2.64(\mathrm{~s}$, $2 \mathrm{H}), 2.66-2.84(\mathrm{~m}, 1 \mathrm{H}), 3.03(\mathrm{~d}, J=12.6 \mathrm{~Hz}, 3 \mathrm{H}), 3.09-3.18(\mathrm{~m}, 1 \mathrm{H}), 3.18(\mathrm{~s}, 3 \mathrm{H}), 3.36(\mathrm{~d}, J$ $=12.2 \mathrm{~Hz}, 1 \mathrm{H}), 3.42(\mathrm{~d}, J=9.0 \mathrm{~Hz}, 1 \mathrm{H}), 3.86(\mathrm{~s}, 2 \mathrm{H}), 3.93-4.08(\mathrm{~m}, 1 \mathrm{H}), 4.45(\mathrm{dd}, J=12.0$, $2.8 \mathrm{~Hz}, 1 \mathrm{H}), 5.27(\mathrm{q}, 1 \mathrm{H}), 5.42-5.58(\mathrm{~m}, 1 \mathrm{H}), 5.85(\mathrm{~d}, J=1.3 \mathrm{~Hz}, 1 \mathrm{H}), 6.40-6.61(\mathrm{~m}, 4 \mathrm{H})$, $6.81(\mathrm{~s}, 1 \mathrm{H}), 7.12(\mathrm{~d}, J=1.8 \mathrm{~Hz}, 1 \mathrm{H})$. 
DM-CO-(CH2) 3 -SMe (12b): DM-CO- $\left(\mathrm{CH}_{2}\right)_{3}-\mathrm{SH}(5 \mathrm{mg}, 6.65 \mu \mathrm{mol})$, was dissolved in anhydrous DMF $(0.3 \mathrm{~mL})$ to which was added DIPEA $(3.57 \mu \mathrm{L}, 0.020 \mathrm{mmol})$ and iodomethane $(1.2 \mu \mathrm{L}, 0.020 \mathrm{mmol})$ with magnetic stirring at room temperature. After $1 \mathrm{~h}$ the crude solution was purified on a XDB-C18, 21.2 x $5 \mathrm{~mm}, 5 \mu \mathrm{m}$ column with a flow rate $20 \mathrm{ml} / \mathrm{min}$. Using deionized water with $0.1 \%$ formic acid and linear gradient of acetonitrile from $5 \%$ to $95 \%$ over $30 \mathrm{~min}$ at $20 \mathrm{ml} / \mathrm{min}$. Fractions containing desired product were combined, frozen then lyophilized to give $1 \mathrm{mg}$ (19\% yield) of a white solid. HRMS $(\mathrm{M}+\mathrm{H})^{+}$calcd. 766.3135 , found 766.3121. ${ }^{1} \mathrm{H}$ NMR (400 MHz, DMSO-d6) $\delta 0.71(\mathrm{~s}, 3 \mathrm{H}), 1.08(\mathrm{dd}, J=18.1,6.6 \mathrm{~Hz}, 7 \mathrm{H}), 1.18$ $(\mathrm{d}, \underline{J}=12.9 \mathrm{~Hz}, 1 \mathrm{H}), 1.30-1.47(\mathrm{~m}, 2 \mathrm{H}), 1.53(\mathrm{~s}, 3 \mathrm{H}), 1.56-1.68(\mathrm{~m}, 1 \mathrm{H}), 1.68-1.78(\mathrm{~m}, 1 \mathrm{H})$, $1.78(\mathrm{~s}, 3 \mathrm{H}), 1.91-2.05(\mathrm{~m}, 1 \mathrm{H}), 2.18-2.31(\mathrm{~m}, 1 \mathrm{H}), 2.33-2.41(\mathrm{~m}, 2 \mathrm{H}), 2.63(\mathrm{~s}, 3 \mathrm{H}), 2.73(\mathrm{~d}$, $J=9.7 \mathrm{~Hz}, 1 \mathrm{H}), 3.05(\mathrm{~s}, 3 \mathrm{H}), 3.18(\mathrm{~s}, 4 \mathrm{H}), 3.33-3.48(\mathrm{~m}, 2 \mathrm{H}), 3.86(\mathrm{~s}, 3 \mathrm{H}), 4.00(\mathrm{t}, J=11.5$ $\mathrm{Hz}, 1 \mathrm{H}), 4.45(\mathrm{dd}, J=12.1,2.8 \mathrm{~Hz}, 1 \mathrm{H}), 5.28(\mathrm{q}, J=6.7 \mathrm{~Hz}, 1 \mathrm{H}), 5.43-5.57(\mathrm{~m}, 1 \mathrm{H}), 5.85$ (s, $1 \mathrm{H}), 6.41-6.62(\mathrm{~m}, 3 \mathrm{H}), 6.81(\mathrm{~s}, 1 \mathrm{H}), 7.12(\mathrm{~d}, J=1.8 \mathrm{~Hz}, 1 \mathrm{H}), 8.47(\mathrm{~s}, 1 \mathrm{H})$.

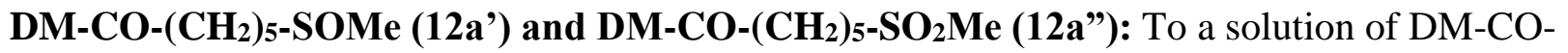
$\left(\mathrm{CH}_{2}\right)_{3}-\mathrm{SCH}_{3}(\mathbf{1 2 a}, 100 \mathrm{mg}, 0.133 \mathrm{mmol})$ in ethanol $(1.0 \mathrm{~mL})$ were added vanadyl acetylacetonate $(11 \mathrm{mg}, 0.041 \mathrm{mmol})$ and a solution of $5.5 \mathrm{M}$ tert-butyl hydrogen peroxide in decane $(36 \mu \mathrm{L}, 0.19 \mathrm{mmol})$ at ambient temperature. The reaction mixture was stirred for $1 \mathrm{~h}$ and was purified by preparative HPLC. Fractions containing the racemic sulfoxide 12a' were combined, frozen, and lyophilized to give $40 \mathrm{mg}$ (39\% yield) of 12a' as a white solid. Also fractions containing the sulfone 12a" were combined, frozen and lyophilized to give $20 \mathrm{mg}$ ( $18 \%$ yield) of 12a" as a white solid. Analytical data for 12a': HRMS: $(\mathrm{M}+\mathrm{Na})+832.3222$; found 832.3228; ${ }^{1} \mathrm{H}$ NMR (400 MHz, DMSO-d6) $1 \mathrm{H}$ NMR (400 MHz, DMSO-d6) $\delta 0.71(\mathrm{~d}, J=$ $4.2 \mathrm{~Hz}, 3 \mathrm{H}), 1.05(\mathrm{~d}, J=6.4 \mathrm{~Hz}, 2 \mathrm{H}), 1.10(\mathrm{~d}, 4 \mathrm{H}), 1.18(\mathrm{~d}, J=13.2 \mathrm{~Hz}, 1 \mathrm{H}), 1.22-1.33(\mathrm{~m}$, $1 \mathrm{H}), 1.33-1.51(\mathrm{~m}, 3 \mathrm{H}), 1.53(\mathrm{~s}, 3 \mathrm{H}), 1.92-2.01(\mathrm{~m}, 1 \mathrm{H}), 2.04-2.17(\mathrm{~m}, 1 \mathrm{H}), 2.37(\mathrm{~d}, J=1.5$ $\mathrm{Hz}, 5 \mathrm{H}), 2.46-2.55(\mathrm{~m}, 1 \mathrm{H}), 2.63(\mathrm{~s}, 3 \mathrm{H}), 2.69-2.80(\mathrm{~m}, 1 \mathrm{H}), 3.02(\mathrm{~s}, 4 \mathrm{H}), 3.14(\mathrm{~s}, 1 \mathrm{H}), 3.18$ $(\mathrm{s}, 3 \mathrm{H}), 3.25(\mathrm{~s}, 4 \mathrm{H}), 3.34-3.46(\mathrm{~m}, 2 \mathrm{H}), 3.86(\mathrm{~s}, 3 \mathrm{H}), 4.00(\mathrm{t}, J=12.2,10.5,2.2 \mathrm{~Hz}, 1 \mathrm{H}), 4.45$ $(\mathrm{dd}, J=12.1,2.8 \mathrm{~Hz}, 1 \mathrm{H}), 5.28(\mathrm{q}, J=6.7 \mathrm{~Hz}, 1 \mathrm{H}), 5.45-5.54(\mathrm{~m}, 1 \mathrm{H}), 5.85(\mathrm{~s}, 1 \mathrm{H}), 6.44-$ $6.60(\mathrm{~m}, 4 \mathrm{H}), 6.82(\mathrm{~s}, 1 \mathrm{H}), 7.13(\mathrm{~d}, J=2.0 \mathrm{~Hz}, 1 \mathrm{H})$. Analytical data for 12a": HRMS: calcd. for $(\mathrm{M}+\mathrm{Na})+848.3175$; found 848.3163, 1H NMR (400 MHz, DMSO-d6) $\delta 0.71(\mathrm{~s}, 2 \mathrm{H}), 1.05(\mathrm{~d}, J$ $=6.4 \mathrm{~Hz}, 2 \mathrm{H}), 1.10(\mathrm{~d}, J=6.8 \mathrm{~Hz}, 3 \mathrm{H}), 1.13-1.31(\mathrm{~m}, 2 \mathrm{H}), 1.32-1.46(\mathrm{~m}, 2 \mathrm{H}), 1.53(\mathrm{~s}, 3 \mathrm{H})$, 1.89 (s, 3H), $2.03-2.17(\mathrm{~m}, 1 \mathrm{H}), 2.26(\mathrm{p}, J=1.8 \mathrm{~Hz}, 2 \mathrm{H}), 2.60(\mathrm{p}, J=2.0 \mathrm{~Hz}, 1 \mathrm{H}), 2.64(\mathrm{~s}, 3 \mathrm{H})$, $2.72(\mathrm{~s}, 3 \mathrm{H}), 2.82(\mathrm{~s}, 3 \mathrm{H}), 2.88(\mathrm{~s}, 3 \mathrm{H}), 3.02(\mathrm{~s}, 2 \mathrm{H}), 3.18(\mathrm{~s}, 3 \mathrm{H}), 3.22(\mathrm{~s}, 3 \mathrm{H}), 3.33-3.45(\mathrm{~m}$, 2H), $3.86(\mathrm{~s}, 3 \mathrm{H}), 4.00(\mathrm{t}, J=11.2 \mathrm{~Hz}, 1 \mathrm{H}), 4.45(\mathrm{dd}, J=12.1,2.8 \mathrm{~Hz}, 1 \mathrm{H}), 5.28(\mathrm{q}, J=6.8 \mathrm{~Hz}$, $1 \mathrm{H}), 5.43-5.57(\mathrm{~m}, 1 \mathrm{H}), 5.85(\mathrm{~d}, J=1.5 \mathrm{~Hz}, 1 \mathrm{H}), 6.43-6.59(\mathrm{~m}, 3 \mathrm{H}), 6.82(\mathrm{~s}, 1 \mathrm{H}), 7.13(\mathrm{~d}, J=$ $2.0 \mathrm{~Hz}, 1 \mathrm{H})$. 


\section{General procedure for the preparation of immolative ADCs.}

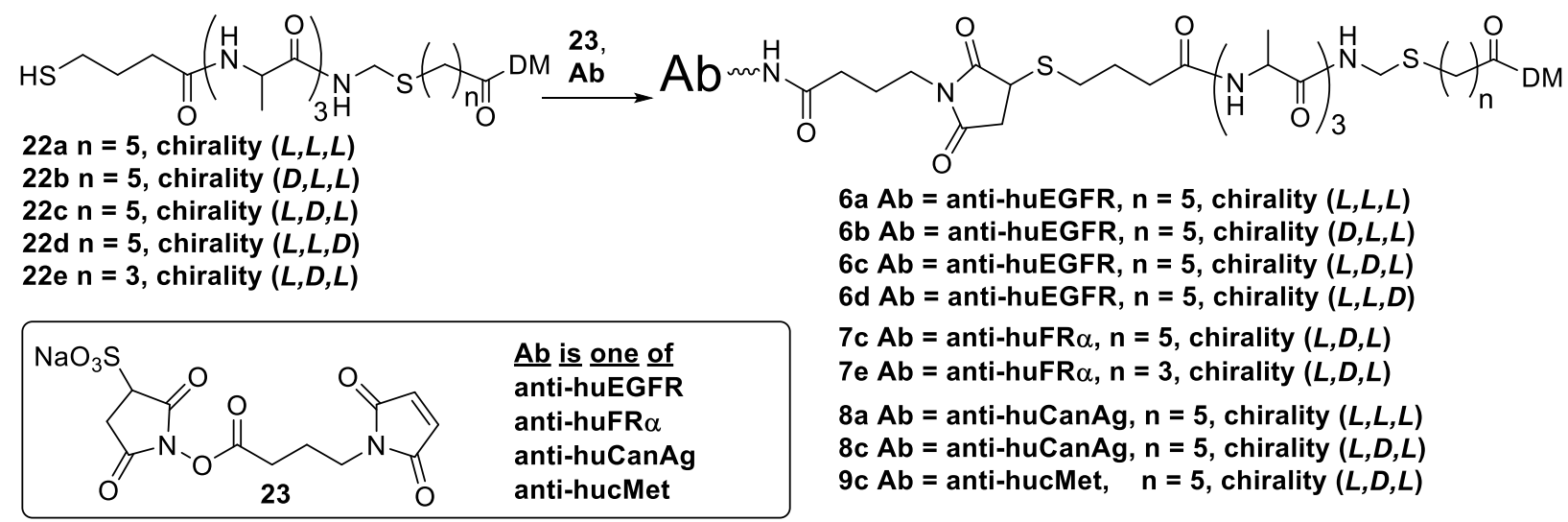

Figure S 4 Preparation of immolative ADC: The right most amino acid of the linker is attached to the immolative nitrogen example: (L, L, D) indicates a D-Alanyl residue is attached to the immolative nitrogen)

Preparation of Maytansinoid Solution: Sulfo-GMBS (23) and one of the thiol-bearing maytansinoids $(\mathbf{2 2 a}-\mathbf{2 2 e})$ were dissolved in a solution of 3:7 (50 mM sodium succinate, $\mathrm{pH} 5.0$ : DMA) to give a concentration of $1.5 \mathrm{mM}$ and $1.9 \mathrm{mM}$ of each, respectively. The solution was gently stirred at room temperature for $30 \mathrm{~min}$ then excess thiol was quenched by bringing the solution to $0.5 \mathrm{mM}$ in $N$-ethyl maleimide with gentle stirring for $10 \mathrm{~min}$. Used for conjugation to antibody without isolation. Samples of each reaction were analyzed by LRMS direct injection.

HPLC/LRMS (sulfo-GMBS with 22a M - Na)- calcd. 1482.4, found 1482.7;

HPLC/LRMS (sulfo-GMBS with 22b M - Na)- calcd. 1482.4, found 1482.3; HPLC/LRMS (sulfo-GMBS with 22c M - Na)- calcd. 1482.4, found 1482.6; HPLC/LRMS (sulfo-GMBS with 22d M - Na)- calcd. 1482.4, found 1482.6; HPLC/LRMS (sulfo-GMBS with 22e M - Na)- calcd. 1454.5, found 1454.8;

Preparation of immolative ADC: To a solution of antibody $(2.5 \mathrm{mg} / \mathrm{mL})$ in $60 \mathrm{mM}$ EPPS containing $15 \%$ by volume $N, N$-dimethylacetamide (DMA), $\mathrm{pH} 8.0$ was added 6.5 mol equiv. of the corresponding maytansinoid solution. After $16 \mathrm{~h}$ the reaction mixture was purified using a NAP-G25 column that was pre-equilibrated and run with $10 \mathrm{mM}$ sodium succinate, $\mathrm{pH}$ 5.5, 250 $\mathrm{mM}$ glycine, $0.5 \%$ sucrose, and $0.01 \%$ Tween-20 buffer. Analyses were described or referenced in the main text. The binding of ADCs to target cells were approximately half that of the corresponding naked antibody. The representative binding affinity of ADCs to T47D cells is shown in Figure S 5. All conjugates in these studies were formulated at $2.0 \mathrm{mg} / \mathrm{mL}$, unless 
otherwise stated, and had a similar average drug to antibody ratio (DAR) in the range of $3.8-$ 4.0. Analyses showed that all conjugates contained less than $2 \%$ aggregate and endotoxin units (EU) were $<0.2 \mathrm{EU} / \mathrm{mg}$.

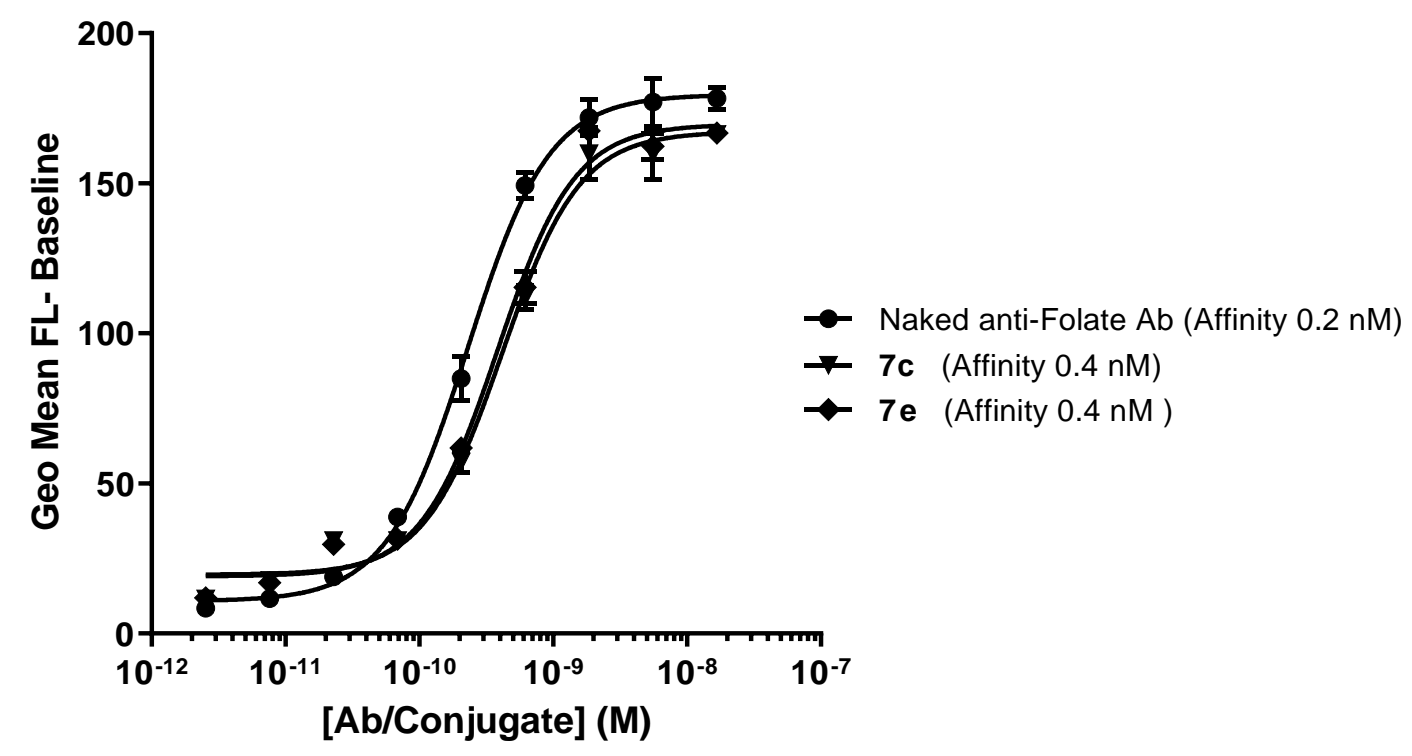

Figure S 5 Binding affinity of representative ADCs to target antigen on T47D cells

\section{In vitro cytotoxicity:}

A Victor3 luminescence plate reader was used in cell assays to measure luminescence.

The procedure for determining cytotoxic potencies were assessed in flat-bottomed 96 well plates (Costar) using a water-soluble tetrazonium salt (WST-8) based cell viability assay (Dojindo, Molecular Technologies, Inc.) is referenced in the main text and described briefly here. Human tumor cells (1,000-5,000 cells/well, depending on the cell line), in the appropriate culture medium, were incubated with conjugates in the presence or absence of an excess of the corresponding unconjugated antibodies, or with the metabolites for 5 days, at $37{ }^{\circ} \mathrm{C}, 6 \% \mathrm{CO}_{2}$. Cell viability was determined from background-corrected WST-8 absorbance.

Table S 1 ADC Cytotoxicities

\begin{tabular}{cccc}
\hline & \multicolumn{3}{c}{$\mathrm{IC}_{50}(\mathrm{nM})$} \\
\cline { 2 - 4 } ADC & KB & Igrov-1 & Jeg-3 \\
\hline 1b & 0.5 & 2.0 & 5.0 \\
4b & 0.2 & 0.3 & 0.2 \\
7e & 0.3 & 50 & 0.7 \\
7c & 0.3 & 7.1 & 0.6 \\
\hline
\end{tabular}




\section{Bystander cell killing assays:}

Cell Titer Glo and One Glo reagents were purchased from Promega. The ability of ADCs to induce bystander killing was determined by one of two assays. Both assays were performed in Ubottomed 96-well plates (Costar) to keep mixed $\mathrm{Ag}$ - and $\mathrm{Ag}+$ cells in close proximity to each other.

Bystander killing assay 1: MCF7 Ag- cells (1500 cells per well) in the appropriate culture media were incubated in wells of a U-bottomed 96 well plate with the designated number of $\mathrm{HCC} 827 \mathrm{Ag}+$ cells and $\mathrm{ADC}(1.1 \mathrm{nM})$ for 5 days, at $37^{\circ} \mathrm{C}, 6 \% \mathrm{CO}_{2}$. The concentration of conjugate used in the assay was high enough to kill all $\mathrm{Ag}+$ cells but not able to kill $\mathrm{Ag}$ - cells unless Ag+ cells were also present. On day 5, cell viability was determined by Cell Titer Glo assay according to the manufacturer's protocol. Data was plotted as relative luminescence units (RLU) vs. number of Ag+ cells plated in the mixed culture.

Bystander killing assay 2: Wells in a U-bottomed 96 well plate were plated with a mixture of $1500 \mathrm{Ag}-\mathrm{Nam} / \mathrm{luc}$ cells and the designated number of Jeg-3 Ag+ cells in the appropriate culture media. The mixed cell culture was treated with the corresponding ADC $(2 \mathrm{nM})$ or with no added ADC for 4 days at $37{ }^{\circ} \mathrm{C}, 6 \% \mathrm{CO}_{2}$. Viability of Ag- Nam/luc cells was determined by One Glo assay according to the manufacturer's protocol. The percent surviving Ag- cells was calculated relative to the untreated control (mixed culture of positive and negative cells not exposed to the conjugates). The percent surviving $\mathrm{Ag}$ - cells was plotted vs the number of $\mathrm{Ag}+$ cells in the plated mixed culture.

\section{In vivo efficacy in xenograft models:}

Female CB.17 SCID mice at 6 weeks of age were received from Charles River Laboratories. All in vivo procedures were performed in strict accordance with the NIH Guide for the Care and Use of Laboratory Animals. The in vivo efficacy of ADCs were evaluated in Hs746T, HT-29 or OV90 tumor xenograft models. Female SCID mice were inoculated subcutaneously in the right flank with the desired cell type in 1:1 ratio of serum-free medium/matrigel $\left(1 \times 10^{7}\right.$ cells/mouse for OV90 and $5 \times 10^{6}$ for Hs746T and HT29). The animals were then randomly distributed into groups of 8 mice per group for the Hs746T study and 6 mice per group for the HT-29 and OV-90 studies. Control mice were treated with phosphate-buffered saline vehicle. The required concentrations of ADCs were made by diluting stock samples with vehicle. Xenografts were grown to $\sim 100 \mathrm{~mm}^{3}$, then mice were administered ADC or vehicle by tail vein intravenous (i.v.) injection ( $200 \mu \mathrm{L} /$ mouse). All dosing was based on the weight of the antibody component of the conjugate. Tumor sizes were measured twice weekly in three dimensions using a caliper with tumor volumes expressed in $\mathrm{mm}^{3}$ calculated using the formula $\mathrm{V}=1 / 2$ (length $\times$ width $\times$ height). Body weight was also measured twice per week. Data from these studies was interpreted using the following definitions: Partial regression (PR), greater than 50\% reduction of tumor xenograft size; Complete regression (CR), tumor xenograft no longer detected. 


\section{In vivo tolerability:}

The acute toxicity of ADCs (formulated at $4 \mathrm{mg} / \mathrm{mL}$ ) were evaluated in CD-1 mice by monitoring body weight loss and clinical observations over 14 days following a single dose i.v. injection via tail vein. Maximum tolerated dose (MTD) is defined as the highest dose at which no animals died or were required to be sacrificed due to $>20 \%$ body weight loss or signs of distress or morbidity (hunching, lack of movement, inability to eat or drink, or signs of pain/distress).

\section{Pharmacokinetic studies :}

Six non-tumor bearing CD-1 mice were dosed (i.v., single bolus) with $10 \mathrm{mg} / \mathrm{kg}$, (protein dose) of 7c. Blood samples were collected at various time intervals, from which antibody concentrations were determined by ELISA for the antibody (irrespective of maytansinoid loading), and conjugate concentrations were determined using a sandwich ELISA that captures the maytansinoid component and detects the antibody component as referenced in the main text. The conjugate concentration ELISA involves the capture of ADC bearing at least one attached maytansinoid using an anti-maytansinoid antibody then the antibody of the conjugate is detected with an enzyme-labeled anti-Fc antibody. In order to be detected, a conjugate must contain at least one covalently linked maytansinoid. The total antibody, antibody bearing at least one maytansinoid as well as antibody with no attached maytansinoids, is determined by capturing it with an anti-human IgG antibody then quantitated using an enzyme labeled anti-human $\operatorname{IgG}$ antibody. Pharmacokinetic parameters were calculated using Pharsight WinNonLin software.

\section{Full list of immolative ADC 7c Pharmaco Kinetic results:}

PK parameters for the antibody component of the immolative ADC 7c, whether it is bound to drug or not, are as follows: $C_{\max }$ of $153 \mu \mathrm{g} / \mathrm{mL}, T_{1 / 2}$ of 15.2 days, AUC0-inf 1306 day* $\mu \mathrm{g} / \mathrm{mL}$, and $C l$ of $7.4 \mathrm{~mL} / \mathrm{day} / \mathrm{kg}$. The PK parameters for a conjugate that contains at least one covalently linked maytansinoid are as follows: $C_{\max } 188 \mu \mathrm{g} / \mathrm{mL}, T_{1 / 2}$ of 10.9 days, AUC0-inf 1019 day* $\mu \mathrm{g} / \mathrm{mL}$, and $\mathrm{Cl}$ of $9.6 \mathrm{~mL} / \mathrm{day} / \mathrm{kg}$. 